Contextualizing Writing Centres: Theory vs. Practice

\author{
Philip J. Sloan \\ School of Linguistics and Applied Language Studies \\ Carleton University, Ottawa
}

\begin{abstract}
April, 2007
A thesis submitted to the Faculty of Graduate Studies and Research in partial fulfilment of the requirement for the degree of Master of Arts Applied Language Studies
\end{abstract}

C Philip J. Sloan, 2007 


$\begin{array}{ll}\begin{array}{l}\text { Library and } \\ \text { Archives Canada }\end{array} & \begin{array}{l}\text { Bibliothèque et } \\ \text { Archives Canada }\end{array} \\ \begin{array}{l}\text { Published Heritage } \\ \text { Branch }\end{array} & \begin{array}{l}\text { Direction du } \\ \text { Patrimoine de l'édition }\end{array} \\ \begin{array}{l}\text { 395 Wellington Street } \\ \text { Ottawa ON K1A 0N4 } \\ \text { Canada }\end{array} & \begin{array}{l}\text { 395, rue Wellington } \\ \text { Ottawa ON K1A ON4 } \\ \text { Canada }\end{array}\end{array}$

Your file Votre référence ISBN: 978-0-494-26967-1 Our file Notre référence ISBN: 978-0-494-26967-1

NOTICE:

The author has granted a nonexclusive license allowing Library and Archives Canada to reproduce, publish, archive, preserve, conserve, communicate to the public by telecommunication or on the Internet, loan, distribute and sell theses worldwide, for commercial or noncommercial purposes, in microform, paper, electronic and/or any other formats.

The author retains copyright ownership and moral rights in this thesis. Neither the thesis nor substantial extracts from it may be printed or otherwise reproduced without the author's permission.
AVIS:

L'auteur a accordé une licence non exclusive permettant à la Bibliothèque et Archives Canada de reproduire, publier, archiver, sauvegarder, conserver, transmettre au public par télécommunication ou par l'Internet, prêter, distribuer et vendre des thèses partout dans le monde, à des fins commerciales ou autres, sur support microforme, papier, électronique et/ou autres formats.

L'auteur conserve la propriété du droit d'auteur et des droits moraux qui protège cette thèse. $\mathrm{Ni}$ la thèse ni des extraits substantiels de celle-ci ne doivent être imprimés ou autrement reproduits sans son autorisation.
In compliance with the Canadian

Privacy Act some supporting forms may have been removed from this thesis.

While these forms may be included in the document page count, their removal does not represent any loss of content from the thesis.
Conformément à la loi canadienne sur la protection de la vie privée, quelques formulaires secondaires ont été enlevés de cette thèse.

Bien que ces formulaires aient inclus dans la pagination, il n'y aura aucun contenu manquant.

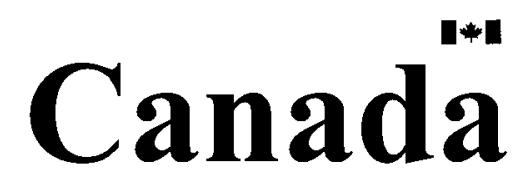




\begin{abstract}
This large-scale triangulated inquiry combines reflections of tutors and writing centre directors, direct session observations, and an online survey to identify, examine, and question the shared epistemological assumptions underlying common pedagogical approaches in writing centres. Context-based theories of learning and knowing are used to illuminate the inherent contradictions in these approaches and the ways in which tutors deal with said contradictions. Results point to the highly contextualized nature of writing centre work, indicating that tutors not only use methods that fundamentally contradict holistic writing center ideology, but use them effectively. It is suggested that writing centres reevaluate themselves in light of these findings and promote a reciprocal relationship between theory and practice.
\end{abstract}


Abstract...........................................................ii

Table of Contents...............................................iii

Chapter 1: Introduction........................................1

Chapter 2: Context of the Study..................................4

Chapter Overview

The Need

Reflective Practice

Tutor Voices

Multiple Spaces

Theoretical Constructions of Writing Centers

Defining Ourselves

The Idea of a Writing Center

Tutoring Manuals

Theoretical Orientation of the Study

Reflective Practice and Knowing-in-action

Double Binds

Previous Research/Literature Review

Role of the tutor - peer?

Directive/Non-directive Tutoring

Tutoring Non-Native Speakers

On the Whole

Chapter 3: Methodology

Chapter Overview

Introduction

Reflections

Participants

Procedure/Data Collection

Direct Session Observations

Setting

Participants

Procedure/Data Collection

Survey

Participants

Procedure/Data Collection

Chapter 4: Results and Discussion.

Chapter Overview

Shared Ideals

"Producing Better Writers"

Tutor Talk

Student-centeredness 
"Social Keenness"

Survey Data - Shared Ideals

Synopsis

Contradictions, Divergent Expectations, and Double Binds

Learning to Write and Writing to Learn

Process and Product

Change

Collaboration (or lack thereof) and Defensive Rhetoric

Survey Data - Double Binds

Synopsis

Directive Tutoring

Double Binds Precipitating Directive Tutoring

Tutorial Role Conflict

Leading Questions and "Delayed Directive Tutoring"

Why are Tutors Directive?

NNS/Advanced Students

Guilty of Being Directive?

Survey Data - Directive Tutoring

Synopsis

The Order of Concerns

Familiarity with the Order of Concerns

Changing the Order of Concerns

Double Binds

Coping with Double Binds: How Do Tutors React?

Double Binds and NNS Students

Order of Concerns and Directiveness

Survey Data - The Order of Concerns

Synopsis

How Do We Define Ourselves? Adaptability and Contextual Response

"A Universe of One"

Experience

The Art of Tutoring

Raw Survey Data

Table 1

On the Whole

Chapter 5: Conclusion

Chapter Overview

Introduction

Shared Ideals

Tutor Talk

"Social Keenness"

Double Binds

Directive/Non-Directive Tutoring

Conflicted Role of "Peer"

Process and Product

Order of Concerns - NNS Writers 


\section{Writing to Learn}

Defïning Ourselves: Are We Really a Service?

Closing Comments

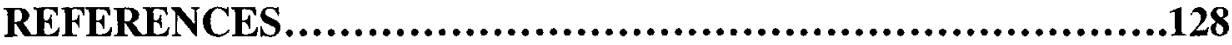

APPENDIX A..................................................137

APPENDIX B.......................................................139

APPENDIX C....................................................141

APPENDIX D....................................................142

APPENDIX E...............................................148 


\section{CHAPTER ONE}

\section{INTRODUCTION}

It feels good to be a tutor. We talk. We listen. We engage in productive dialogue to facilitate self-actualization amongst our students. We understand that writing is a process, one that can provoke unexpected connections and bring order to confusion. We are holistic and Socratic in our approach. We encourage students to ask questions, develop their own ideas, and, ideally, awaken in each of them a sense of existential individuality. We are student-centered and constructivist, working with writers to find and create meaning in a rhetorical void. Instead of showing tutees the world, we immerse them in it, allowing them to define a world of their own. We help students to help themselves. We are, in the seminal words of Stephen North, producing "better writers, not better writing" (438). Feels good, doesn't it?

Writing centres stand resolutely as the very embodiment of the writing-as-process movement, informed by a pedagogical approach that favors means rather than ends, remaining dedicated - unflinchingly - to the idea that writing is neither fixed nor final, but rather an ongoing construction of knowledge. Unfortunately, writing centre reality can sometimes belie this idealized tutor-student relationship. Indeed, it "does come as a shock when, having been led by your training to expect some deep, unalloyed, genuine engagement - some eager wrestler of texts - you meet instead a frightened freshman who seems only to want a super proofreader" (North 11). As many teachers of writing have come to understand, theory is not always adequate to describe what actually occurs in practice. Contradictions sometimes arise between what is theoretically best for a writer and what that writer actually wants or needs. Nowhere is this more evident than in a 
writing centre tutorial session, where situational constraints push the boundaries of collaborative, process-driven theories of writing, challenging tutors to break the proverbial ties that bind (in this case, the foundational principles of writing centre philosophy to which they so rigidly adhere).

Linda Shamoon and Deborah Burns assert that it is often "ideology rather than examined practice" that informs writing centre tutoring methodology (136). They describe our shared ideals - rooted primarily in tutoring manuals and articles in Writing Center Journal and Writing Lab Newsletter - as something of a "writing center bible," acting "more like articles of faith that serve to validate a tutoring approach which "feels right" (135). Paula Gillespie and Neal Lerner are also cognizant of this potential problem, noting that "these ideologies are rarely critiqued; instead, many of us just express certain beliefs as the right way to do things" (51). What we are left with is what Angela Petit calls a "purified space," a place where the "discourses presented to tutors seem as impermeable as the walls of the center itself' (114).

From the earliest stages of their training, tutors are effectively indoctrinated with process-driven, facilitative ideals. Tutor-centered learning: bad. Student-centered learning: good. Focusing on sentence-level mechanics: bad. Content-driven dialogue: good. A tutor is a peer who facilitates, not an editor who directs and proofreads. In the writing centre community, theory has served us well; we know the "rules," and seem inclined to constantly define and re-define them. What is missing is an understanding of if and when - in light of contradictory circumstances - the rules can be broken.

The purpose of this study is to explore these discrepancies in much greater depth, looking at writing centre philosophy as it manifests itself in both theory and practice. In 
a large-scale triangulated inquiry combining reflections of tutors and writing centre directors, direct session observations, and an online survey, I will identify, examine, and question the shared epistemological assumptions underlying our methodological approaches, the contradictions inherent in those approaches, and the ways in which tutors deal with said contradictions.

\section{Research questions:}

1) How does the theoretical "idea" of a writing centre manifest itself in day-to-day writing centre reality?

2) How - and how frequently - do tutoring sessions devolve into situations that contradict our shared philosophy?

3) How bound are we by our shared ideals?

4) Is it ever appropriate to use methods/techniques that are at odds with the very foundation of our approach?

5) Is there a disparity between the "idea" and the reality of a writing centre?

The study will answer a widespread call for reflective practice in the field of education. In addition, it will serve to fill gaps in current writing centre scholarship by examining multiple spaces and privileging voices of the tutors themselves in the analysis. Moreover, it represents a movement towards convergence of theory and practice in the field of writing studies. 


\section{CHAPTER TWO \\ CONTEXT OF THE STUDY}

\section{Chapter Overview}

This chapter will illustrate the importance of my study, provide a theoretical background for it, and situate it within the professional discourse about writing centres. It is divided into four sections. The first will look at the need for this type of research, as voiced by educators and those directly involved with writing centres. The second and third sections develop a firm theoretical base for my ideas and data analysis; the second focuses on theoretical constructions of writing centres, exploring the nature and basis of the ideals shared by the writing centre community, while the third deals with notions of reflection and double binds vis-à-vis theories of learning and knowing that will be used in interpreting the data. The fourth section will examine previous research in the field and the gaps my study hopes to fill.

\section{The Need}

This study fulfills a need as it answers a call for reflection on the part of instructors across the curriculum. Furthermore, it fills a gap in writing centre scholarship due to its scope (multiple centres, rather than one space) and its focus on the voices of the tutors.

\section{Reflective Practice}

The primary source of data in this study is tutor reflections. The need for teacher/tutor reflection is repeatedly emphasized, not just by writing centre theorists, but by educators across the disciplines. George Hillocks, Jr. asserts that "effective teaching 
of writing is reflective, continually reexamining assumptions, theories, and their practical applications" (xviii). Stephen D. Brookfield encourages all teachers to engage in "critical reflection," lest we "take action on the basis of assumptions that are unexamined and we believe unquestioningly that others are reading into our actions the meanings we intend" (3-4). Susan Imel pushes for reflective practice, maintaining that it can make us aware of gaps between theory and practice:

The values, assumptions, and strategies supporting ideas about practice need to be examined. If this clarification does not occur, professionals may find themselves in the position of espousing one theory but using another in practice; that is, their actions are not consistent with their intent. In reflective practice, professionals can expose their actions to critical assessment to discover the values and assumptions underlying their practice. As professionals become more aware of their theories-in-use, they become more conscious of the contradictions between what they do and what they hope to do. (2)

Nowhere are these contradictions more evident than in the writing centre. Writing centre theory provides a foundation, a framework that tutors can bring to a session. While it serves that purpose well, the theory doesn't always reflect the extent to which tutors may occasionally cross the lines, lines that we ourselves have drawn. Elizabeth Boquet says, "the at-odds-ness of the discourse so successfully escapes notice, suggesting that contradiction exists, in the minds of those who use it, in the equilibrium that is characteristic of all apparently natural things" ("Our Little Secret" 465). These contradictions point to what many believe is a growing gap between theory and practice: 
The current gap between theory and working actualities is so immense that writing center discourse inaccurately describes what we do, or why we do it, or the benefits we bring to our students, colleagues, and institutions. Dismayingly, our theory has left us with no effective language for [...] describing $[\ldots]$ our contributions to the mission of the university" (Gardner \& Ramsey 26).

Despite attempts (Hobson, Carino) to bridge this gap by expanding our theoretical bases, as Petit says, "the borders persist" (113).

Self-reflection, then, is of paramount importance. Reflection typically "receives long-standing, regular endorsement from writing center professionals" (Bell 82). Peter Vandenburg recommends that we "vigorously promote a self-reflexive attitude amongst out tutors and implicate ourselves in the web of power structures that attempt to control them" $(60)$. Carino insists that we "must maintain critical consciousness about ourselves" (39). Petit suggests that "only through continual self-reflection will we understand how these definitions influence our theorizing about writing centers and our activities within centers" (111). And Barnett simply states, with appropriate brevity, "the time has come for some serious self-reflection" (123).

Foucault claims that the "margins of discourse" offer the best opportunities for self-reflection (Essential). Writing centres exist precisely in those margins, in what Sunstein terms a "state of in-betweenness" (7).

\section{Tutor Voices}

Tutor reflections have been the focus of previous inquiries into writing centres, but most dealt specifically with training, and not necessarily with the implications for the 
writing centre community as a whole. Tutor voices are rarely incorporated into the professional dialogue in any kind of meaningful way. There are, however, a few exceptions. Dinitz and Kiedaisch, in a study similar to my own but limited to one institution, analyzed in great detail the reflections of three tutors on their role as a "peer." The authors see great benefit in the results, asserting:

Writing center theory can be enriched by including tutor voices and perspectives. As the folks at the boundary of theory and practice, tutors are well-positioned to explore the connections between them, to tease out the subtleties, the complications, the assumptions, the omissions in our theory and our practice, and to see how one might shed light on the other.

In their contributions to the edited collection, Writing Center Research: Extending the Conversation, both Kathleen Blake Yancey and Nancy Welch utilize tutor reflections to theorize about writing centre philosophy, but, again, they are limited to the ideas of tutors at only one institution.

\section{Multiple Spaces}

Very few writing centre studies have dealt with data gathered from more than one writing centre space. Writing centre practice is typically explored vis-à-vis one particular writing centre in the form of case studies. Alternately, some researchers have analyzed tutorial sessions in great detail at the micro-level (Clark, "Perspectives"; Thonus, "What are the Differences?"; Blau, Hall, and Strauss, "Exploring"). This research has been invaluable in illuminating what actually occurs in particular writing centres, but not 
necessarily in showing - on a larger scale - the practices, philosophies, and approaches shared by different writing centres.

Writing Centers in Context, by Joyce Kinkead and Jeanette Harris, is one of the few sources to provide a cross-section of different writing centres. The authors collected 12 varied and detailed case studies of writing centres in different institutional contexts. Each study offers an extremely comprehensive snapshot of a particular centre. The studies are limited on their own, but collectively, they say a great deal about the ideals valued and shared by writing centre personnel. The incredibly diverse spaces that are studied reveal a multitude of different approaches to the tutoring process, providing a glimpse of the fragmented and inconsistent nature of writing centre philosophy. Nonetheless, the voices of the tutors themselves remain conspicuously absent from the dialogue.

Certainly, the convergence of many different writing centre inquiries provides a conception of the field as a whole. However, implications for writing centre philosophy are frequently proffered on the basis of inquiry into one space. It is enormously difficult to provide any sort of overarching, collective sense of writing centre identity, but this study - which explores trends as reflected upon in multiple writing centres by both tutors and directors - is a hopeful step in that direction.

\section{Theoretical Constructions of Writing Centres}

This section explores the theoretical underpinnings of writing centres and serves as an introduction to the "shared ideals" of those in the writing centre community. Conceptions of writing centres have been shaped by scholarship in an increasingly 
specific field in which writing center theorists and researchers have "constructed," through theory, fundamental notions of what writing centres ought to do.

\section{Defining Ourselves}

Many articles on or related to writing centres strive for self-definition, on defining or redefining ourselves. Ede ("Writing"), Hemmeter ("Smack"), and Carino ("Metaphors") all identify definition as an important issue for the writing centre community. In fact, it is rare to find an article that does not begin with an obligatory statement of writing centre philosophy. "It is," as Thomas Hemmeter says, "as if each theorist must begin anew the process of awakening the slumbering writing center profession to the need for self-creation" (36).

There is, as many theorists have observed, a risk of over-definition. Petit says, "Classifying writing centers has become so much a part of the discourse that the definitions seem less a discursive tool to help us understand how centers function than a pre-existing fact, one that we are bound (my emphasis) to acknowledge and that determines, even inhibits, how we talk about centers" (113). Carino pejoratively states that, "the notion of definition smacks of closure, completion, of death" (40). Boquet agrees, arguing that, "we would do well not to think of the future of writing centers in excessive terms" ("Our Little Secret" 478).

My interest is in clarification, not classification. I seek to define writing centres only through their shared ideology towards tutoring, and the extent to which said ideology is ingrained in the tutors who practice it. Sue Dinitz and Jean Kiedaisch state, "largely left out of these constructions are tutor voices" (63). Ironically, the tutors, around whom all this theory is centered, rarely have an opportunity to participate in the 
discourse. Through this study, tutors themselves are given a much-needed voice in the scholarly conversations about writing centres. My intent is to explore writing centre values and theories, both as they are articulated through the experiences/reflections of tutors/directors and as they manifest themselves in actual sessions. This provides a philosophical and theoretical base on which to ground my discussion of "double binds" (see: Theoretical Orientation of the Study, p. 20) in relation to practice. Many, if not most, articles on or relating to writing centres strive for self-definition and perspective, but only a comparative few deal specifically with these confusing contradictions.

\section{The Idea of a Writing Center}

Perhaps the most influential piece of writing centre philosophy was propounded in 1984 by preeminent writing centre theorist Stephen North in his landmark polemic, "The Idea of a Writing Center." In the article, North sets out to define the place of the writing centre in academia and exposes widely held misconceptions about writing centres and their holistic mission. Due to endemic ignorance of their history and practice, writing centres were commonly misconstrued as "fix-it shops" for grammar and mechanics or as remedial agencies that deal exclusively with poor writers (436). North admonishes university English departments for perpetuating this distorted image, and goes on to define the new "idea" of a writing centre, whose philosophy is fundamentally at odds with its product-based image. "Writers," North says, "and not necessarily their texts, are what get changed by instruction. Our job is to produce better writers, not better writing" (438).

North's words, his characterization of our "job" as tutors, became practically iconic in writing centre dialogue, serving as the foundational principles of many writing 
centres' methodoiogies. One need look no further than various writing centre websites to see how pervasive North's philosophies have become:

Purdue: Finely-polishing your manuscript would make us better editors, but wouldn't help you become a better writer. ("Writing Lab Information")

Penn State: The Writing Center believes in making better writers, not just better papers. ("Description”)

North Carolina State: We also believe in making better writers and speakers, not better papers and speeches. ("Writing and Speaking")

University of Western Ontario: The goal of the Effective Writing Program is to help members of the community improve as writers, not to improve specific pieces of writing. (“Frequently Asked Questions")

The Writing Centre at Randolph Macon is dedicated to making better writers, not just better writing. ("The Writing Centre")

Saginaw Valley State: The Writing Center is dedicated to developing the writer, not just improving the document. ("Why Visit")

Wilfrid Laurier University: We don't edit your writing; we teach you to become a better writer. ("Wilfrid Laurier Writing Centre")

These websites represent only a handful of examples; North's "idea" of creating "better writers" has been appropriated and incorporated into the mission statement of countless 
writing labs. Some, like Eastern Oregon University, even reference him directly: "We try to give students information and strategies which they can use in future writing (as North reminds us, making better writers, not better papers)" ("Writing Lab Director"). His words have become so ubiquitous, so utterly synonymous with student-centered writing instruction, that they even show up in articles about writing programs; case in point: a 2004 article (see Appendix A for full text) from the USC College Bulletin was titled, "Better Writers (Not Just Better Papers): Students Embrace College Writing Program" (Kim).

North's oft-cited concepts appear in nearly every article about writing centres and in most tutoring manuals, seemingly indicating - at least on the surface - that writing centres are bound rather tightly by their ideals. Our philosophical inclinations towards unequivocal student-centeredness can be traced directly back to North:

The version (of the writing process) we want can only be found, in as yet unarticulated form, in the writer we are working with $[\ldots]$ the best way to describe a writing center tutor's relationship to composing is to say that a tutor is a holist devoted to a participant-observer methodology [...] it follows quite naturally, then, that any curriculum - any plan of action the tutor follows - is going to be student-centered in the strictest sense of that term $[\ldots]$ it will not derive from a generalized model of composing, but will begin where the student is and move where the student moves" ("Idea" 439). 
This unabashedly student-centered view has been widely accepted and adopted as an impermeable truth, so much so that tutors may sometimes have trouble straying from it. Directive tutoring, in contrast, is frowned upon. It is expected that the student - not the tutor - do most of the talking in a session. "Being directive," Therese Thonus says, "is the strongest criticism a writing tutor can levy against self or colleague; it signals "too much' involvement in the student's work" ("Triangulation" 64). This fear of directiveness probably stems from the persistent misconception that tutors edit; as such, providing too much assistance could be construed as "fixing" a paper.

North was also one of the first theorists to explicate the nature of the tutoring process. A tutor, North says, eschews rigid, prescriptive methodologies in favor of openended dialogue. He cites "talk"" as the most elemental component of a session: Nearly everyone who writes likes - and needs - to talk about his or her writing, preferably to someone who will really listen, and knows how to talk about writing, too. Maybe in a perfect world, all writers would have their own ready auditor - a teacher, a classmate, a roommate, an editor who would not only listen but draw them out, asking them questions they would not think to ask themselves. A writing center is an institutional response to this need. (North "Idea" 440)

In a writing centre tutorial session, a tutor's primary function is to "talk about writing with the writer" (441). North, in the spirit of ancient Socratic dialogue, advocates a fluid writing centre dynamic, with thoughtful examination and exchange of ideas and opinions, "a continuous dialectic that is, finally, its own end" (446). This "talk," North asserts, "is everything $[\ldots]$ the lifeblood of a writing center" (443-444). 
North's widely accepted wisdom became the basis of our ideology and ongoing institutional plight. "Idea" has been canonized, not just because North finally put writing centre methodology into words, but also because he "carved out an institutional space where it was necessary" (Boquet "Our Little Secret" 477). North was perhaps the first theorist to give real legitimacy to our practice.

It bears mentioning that North takes an extremely uncompromising position in this essay, pitting $u s$, the writing centre community, against them, those in the academy who have misconstrued our mission. North tells his peers precisely what they "cannot" do:

I have come with experience to take a harder, less conciliatory position [...] teachers, as teachers, do not need, cannot use, a writing center: only writers need it, only writers can use it. You cannot parcel out some portion of a given student for us to deal with [...] nor should you require that all of your students drop by with an early draft of a research paper to get a reading from a fresh audience. You should not scrawl, at the bottom of a failing paper, "Go to the Writing Center." Even those of you who, out of genuine concern, bring students to the writing center, almost by the hand, to make sure that they know we won't hurt them - even you are essentially out of line (440).

North's insists - rather stubbornly - that writing centres be accepted only "on their own terms." (446). This seemed to arouse a sort of collective disenchantment amongst writing centre professionals. He continued his contentious diatribe: "we are not here to serve, supplement, back up, complement, reinforce, or otherwise be defined 
by any external curriculum. We are here to talk to writers" ("Idea" 440). Statements like these marked the beginning of years of defensive rhetoric in writing centre scholarship, in which theorists attempt to show - perhaps even more than what we are what we are not. Petit says of our myriad of definitions, "What binds such varied descriptions together is their representation as alternatives to a polarized other" (112). Riley even worried that as writing centres found their "institutional niche" (26), they would lose sight of their "liberatory and contrarian" mission (29).

Consider the very first of five "rules" for lab tutorials at the Writing Lab at Purdue:

Tutors do not proofread or edit papers: Tutors can help students with any stage of the writing process, from getting started on an assignment to the final stages of revision. They can help students with grammar, but they will not make any changes on a paper, nor will they edit or "fix" a paper for the student. ("Five Major Rules")

This is a "rule" (so-called by the Purdue OWL), not an exception. Writing centres tend to present themselves in such a way, and the defensive stance is readily apparent. This serves as an immediate warning to those with product-based writing in mind. It says, first and foremost, what writing centres do not do. We have defined ourselves against in opposition to - the "fix-it shop" mentality. Similar statements regarding proofreading and editing can be found on almost every single writing centre web site. Gardner and Ramsey addressed this phenomenon:

Regardless of the work actually done in writing centers, the prevailing view of theorists has been that writing specialists do their best work when 
opposing the practices of mainstream education, creating an anti-space where the oppressive and mass template methods of the academy can be undone (26).

Our policies are woven with defensive rhetoric of this ilk; they can cause the ideology to tighten its hold on the tutor and the session, making contradictions all the more cumbersome. Indeed, writing centre practice can be characterized as a conscious and deliberate subversion of mainstream education, as a veritable "anti-curriculum" (Gardner \& Ramsey 27) rooted in our own narratives of resistance.

North himself eventually admitted that "Idea" became something of a "mythology," a "public idealization" ("Revisiting" 9). He reflects upon the article as an overly romanticized vision that concealed "the lived experience of writing centers" $(10)$, lamenting that it "can lay an unnecessarily heavy burden on [...] tutors and writers [...] who take it at anything like face value" (11).

\section{Tutoring Manuals}

Another big influence on writing centre philosophy is tutoring manuals. The ideas espoused within them contribute greatly to our philosophical foundations and serve as the theoretical basis for tutor discourse. While there are many instructional manuals available for the tutor-in-training, a select few have dominated the scene. For a long time, Muriel Harris' Teaching One-to-One: The Writing Conference and Emily Meyer and Louise Z. Smith's The Practical Tutor served this purpose. Though their influence is difficult to quantify, both of these manuals were used widely to train tutors since first being published in the $1980 \mathrm{~s}$. They are products of their times, emphasizing the shift from process to product, but neither book does much to question assumptions (which, 
admittedly, were still being shaped at the time) or account for any larger social or institutional context.

In recent years, Paula Gillespie and Neal Lerner's The Allyn and Bacon Guide to Peer Tutoring has become the unofficial standard for tutoring manuals, frequently used to train tutors and cited in articles about writing centres. While Gillespie and Lerner do take into account the context of a session and repeatedly call for flexibility on the part of the tutor, they perpetuate the myth that "most writers are eager to find meaning in what they write" (23). Furthermore, the notion of tutor as "peer" is somewhat overstated, as if the idea of tutor-as-authoritative teacher is virtually unfathomable, fueling the opposition to directive tutoring. The authors recommend that tutors do no more than $50 \%$ of the talking in a session (103). Tutors are defined extensively in contrast to the role of editor (45-6), another example of the theory focusing on what tutors are not, rather than what they are. With tutorial sessions involving non-native speakers (NNS) of English, Gillespie and Lerner allow some leeway and room to adjust for language differences, but still adhere steadfastly to a process-based, non-directive model of tutoring, suggesting that tutors can and should maintain their usual methods of pedagogy. Notions of NNS writers requiring more direction and/or specific help with grammar are treated as "myths" (119-26).

Gillespie and Lerner do not preclude discussions of specific textual features (grammar, style), but maintain, "these sorts of sentence-level fixes should come later in the process" (17). Mechanics and format are relegated to the status of "lower-order concerns" (17). The Purdue University Writing Lab, which more or less sets the standard for writing centres, also considers grammar and structure to be "lower-order 
concerns" ("HOCs and LOCs" I1). Sentence-level mechanics are typically considered . less important than content issues, and for good reason. Poor grammar can be a symptom of unclear ideas, and it makes little sense to address form - that is, the way ideas are presented - before addressing the ideas themselves. Moreover, there is no point picking apart sentences at this level when the essay has larger issues like lack of focus, poor internal organization of paragraphs, or faulty reasoning. That said, this order of concerns has become ingrained in writing centre ideology, so much so that tutors are sometimes reticent to even look at mechanics at all. We don't want to be construed as a product-based "fix-it shop", and overemphasizing form gives exactly that impression. This hesitance to focus on form, like the reluctance to be directive, is an integral part of who we are.

\section{Theoretical Orientation of the Study}

Selected ideas of Donald Schön and Yrjo Engeström are combined with the aforementioned theoretical constructions of writing centres to provide a framework for the data analysis.

\section{Reflective Practice and "Knowing in Action"}

The value of reflection as a research tool is well established and has long been of interest to educators. Although the writing centre literature calling for reflection is voluminous, "most of it does not address empirically the effectiveness of reflection" (Bell 81). For such a framework, I turn to Donald Schön, social scientist and consultant who, steeped in a reflective tradition supported by Dewey and Piaget, stresses the importance of reflection in helping professionals to learn about and improve their practice (The Reflective Practitioner). 
Schön asserts that abstract theory alone is inadequate to describe the knowledge utilized by most practitioners in context. He laments the "widening rift between research and practice, thought and action" (The Reflective Practitioner viii), encouraging inquiry into the real epistemology of practice, based on close examinations of what practitioners actually do. He equates reflection with "knowing-in-action," a type of implicit "knowhow" that competent practitioners depend on to carry out their work (Educating 25). Professionals may not even be able to describe exactly what they do to accomplish an activity; as Schön says, "skillful action reveals a knowing more than we can say" (The Reflective Practitioner 51). Reflective practice, Schön says, can help us to better understand this implied knowledge.

Schön describes two types of self-reflection. The first, reflection-in-action, occurs during the activity being reflected upon and directly influences it. It is tacit and immediate, allowing a practitioner to deal with "uncertainty, instability, uniqueness, and value conflict" (The Reflective Practitioner 50) within the context of the action. Reflection-in-action is predicated on the simple notion that "knowing" is quite literally in our actions, that knowledge exists in what we do. Judgments and recognitions are carried out spontaneously and often intuitively; reflection-in-action encourages a person to make sense of these phenomena as they occur. When a person reflects-in-action, he/she engages in the acts of thinking and doing at virtually the same time.

The other, reflection-on-action, is more contemplative, and occurs after the activity (The Reflective Practitioner 276). Schön maintains that, "it is [...] possible, by observing and reflecting on our actions, to make a description of the tacit knowing implicit in them" (Educating 25). He describes the benefits of reflection-on-action: 
A practitione;'s reflection can serve as a corrective to overlearning. Through reflection, he can surface and criticize the tacit understandings that have grown up around the repetitive experiences of a specialized practice, and can make new sense of the situations of uncertainty or uniqueness which he may allow himself to experience. (61)

The reflections in this study are of this nature, meant to encourage critical thinking, to make the unconscious more conscious, thus illuminating the tacit aspects of tutoring as "practice." They serve as tangible, analyzable manifestations of "reflection-in-action," refining the concept as something constructive for the reader. Ideally, reflection-on-action can help us to elucidate what Schön termed "the mystique of practical competence" (vii). Without such reflection, he says, there can be "no satisfactory way of describing or accounting for the artful competence which practitioners sometimes reveal in what they do" (The Reflective Practitioner 19).

\section{Double Binds}

Engeström's (Learning) model of development - specifically his notion of "double binds" - is useful for understanding the contradictions experienced by tutors in a tutorial session. The double bind was initially conceived by Gregory Bateson (1956) as a potential cause of schizophrenia. Engeström draws upon Bateson's model of three levels of learning and situates the double bind in an "activity system", the primary unit of analysis in activity theory. David Russell, influenced by the ideas of Engeström, defines an activity system as "any ongoing, object-directed, historically conditioned, dialectically structured, tool-mediated human interaction" (510). Activity theory, originally developed by A.N. Leontev from ideas conceived by Lev Vygotsky, is based on the situatedness of 
human activity, on the notion that cognitive events cannot be extricated from their social context. Engreström's is but one of many subtle variations on this perspective.

For his purposes - and for mine in this paper - double binds refer to the tension created in an activity system due to contradictory goals and interests. Opposing perspectives of objects and motives drive different systems, sometimes against one another in the same activity system. A double bind causes a "clash between the individual actions and the total activity system" (Engeström, Learning 39). Lundell and Beach illustrate the concept of double binds through their study of graduate dissertation writers, who are pulled in opposite directions by their teaching workload and the imperative to address their own research and dissertations ("Dissertation Writers"). When two or more forces operate contrary to each other in such a way, the learner caught in the middle experiences an incongruity known as a "double bind."

For Engeström, the double bind is merely one part of his larger theory of "learning by expanding," which is separated into three levels of learning borrowed from Bateson. Learning I involves learning that is rote or habitual. Learning II entails a kind of metacognitive awareness, a "learning to learn" (3), predominantly in response to contradictions and double binds. Learning III involves dealing directly with these contradictions to develop new, alternative habits and practices. There is a purely theoretical Learning IV, but Engeström notes that it "probably does not occur in any adult living organism on this earth" (3). Engeström is particularly interested in the transition between learning II and learning III:

The outcomes of Learning II, the unconscious habits, frequently and necessarily lead the individual to double bind situations. The habit once 
learned becomes self-defeating in a superficially similar but structurally altered social context; or two mutually exclusive habits seem to be required at the same time. (3)

Learning III involves "conscious self-alteration" based on questioning previously unexamined habits acquired in Learning II (4).

Engeström also touts the benefits of reflection, maintaining that a "reflexive element" (16) is key to understanding double binds. He goes on to say that "learners recognize, define, and reflect on the double bind in order to begin entertaining ways of coping" (17). It is only through identification of and reflection on the double bind that one begins to adapt, eventually conceiving a "created new" that eases the tension (16). Petit, speaking from a writing centre perspective, takes a similar view of such conflicts, saying, "conflict is not a sign of failure; instead, it is an opportunity to negotiate and mediate competing voices, to find meaning and shape identity by learning to speak not within but among discourses" (117).

\section{Previous Research/Literature Review}

For a long time, there were a paltry number of empirical studies with respect to writing centres. That number has been increasing as of late. In terms of more theoretical inquiries, writing centre scholars have debated the relative merits of the same handful of contradictory notions for years. These notions - as well as empirical studies relevant to my research - are discussed in this section.

Role of the Tutor-Peer?

One issue that has been subject to endemic disagreement has been the role of the tutor, especially the extent to which tutors are "peers." In 1983, Sollisch conceptualized 
the peer tutor as a "reading coach" in an ongoing process of collaboration (11). Four years later, John Trimbur, influenced by renowned writing theorist Kenneth Bruffee, published the oft-cited "Peer Tutoring: A Contradiction in Terms," in which he sets the terms "peer" and "tutor" as fundamentally at odds with one another:

How, many good tutors want to know, can I be a peer and a tutor simultaneously? If I am qualified to tutor, then I am no longer a peer to those I tutor. On the other hand, if I am a peer to my tutees, how can I be qualified to tutor? (23)

Trimbur suggests that perhaps these are not "roles to balance," but instead "a temporal sequence to be played out" (26). Muriel Harris supports this notion, observing that as tutors become more competent through practical experience, they tend to become less peer-like ("Collaboration is not Collaboration"). David Healy further explored the ambiguous and sometimes conflicted roles of tutors ("Tutorial Role Conflict"), and subsequent theorists like Irene Lurkis Clark ("Collaboration and Ethics") and Alice Gilliam ("Collaborative Learning Theory") noted further inconsistencies between collaborative theory and writing centre practice.

Lex Runciman questioned whether we should use the word "tutor" at all, claiming that the word's remedial connotation perpetuates misconceptions about writing centre practice. In its place, he suggests we try other words like "writing assistant," "writing consultant," or "writing fellow" (32). William McCall extends this argument, likening tutors to "consultants" and tutorial sessions to "consultations," maintaining that these words better reflect the spirit of collaboration in writing centres (164). 
More recently, Julie Bokser has examined "the problem of peerness" in two separate articles. In the first, Bokser explores the notion of peer vis-à-vis directive tutoring. She senses a degree of aggression and power inherently embedded in the tutortutee dynamic, making the word "peer" - which implies an equal relationship somewhat problematic ("Peer Tutoring and Gorgias"). In the second article, she discusses the tension surrounding three tutors, all of whom have written or edited professionally, and their discomfort with the collaborative role of "peer" ("Am I Really a Peer?").

\section{Directive/Non-Directive tutoring}

The peer issue is really just a part of a larger whole, the ongoing "directive/nondirective continuum" (Clark 33). Writing centre scholarship, since its inception, and especially since North's essay, has endorsed a non-directive, facilitative approach to pedagogy. Thus, the ideal interaction between a student and tutor is thought to be one in which the tutor intervenes as little as possible. Following North's universally recognized axiom - improving the writer rather than the writing - Jeff Brooks articulates this stance even more explicitly: "If our focus is on the writer, directive tutoring is out" (1).

However, some researchers have found that directive tutoring may be more useful and widely practiced than our philosophical base would indicate. Blau, Hall, and Strauss ("Exploring") also performed a linguistic analysis of the tutorial session, finding both directive and non-directive tutoring styles to be effective. The authors believe both strategies are necessary for writers to get the knowledge they need. Shamoon and Burns, struck by "the benefits of a tutoring style that is so opposite our current orthodoxy" (139), urge writing centres to expand their methodology: 
If writing center practices are broadened to include both directive and nondirective tutoring, the result would be an enrichment of tutoring repertoires, stronger connections between the writing center and writers in other disciplines, and increased attention to the cognitive, social and rhetorical needs of writers at all stages of development. (148).

Therese Thonus performed a pair of empirical studies ("Triangulation", "Tutor and Student") that advocate a more pragmatic approach to tutoring. Her sociolinguistic analysis of tutorial sessions showed that tutors often deviated from the "idealized portrayal of their roles" ("Triangulation" 77). She found that tutees typically approached a session with more pragmatic concerns than tutors, creating tension over ownership of text and tutor-student solidarity. Thonus's subsequent study showed that directive tutoring was not only widely practiced, but also helpful to the writer ("Tutor and Student"). In light of these findings, she laments that, "a decontextualized notion of tutor $[\ldots]$ is often reflected in tutorial manuals" ("Triangulation" 59).

Irene Clark, in a quantitative study funded by the National Writing Centers Association, attempted to determine "what directiveness actually means" ("Perspectives" 35). Results indicated a significant difference between student and tutor perceptions of directiveness, with students generally perceiving more directiveness than tutors. Moreover, students who defined themselves as "good" writers tended to perceive less tutor influence over the conference. Essentially, students attributed a more "directive" role to tutors than tutors attributed to themselves, furthering the idea that notions of directiveness should not be constructed in absolute terms. 
Tracy Santa provides an international perspective in a recent exploration of writing centre orthodoxy via her writing centre in the Balkans. She reports that her tutors were "uneasy with conflicting theoretical perspectives," particularly with respect to directive tutoring. While they embraced the process goal of "producing better writers," they found the minimalist, non-directive model to be "anti-intuitive" (30). Like Dinitz and Kiedaisch, she pushes for the writing centre community to invite these tutor perspectives into the professional conversation.

In light of increasing empirical evidence, Teresa B. Henning argues that writing centres should expand beyond the limits of collaborative and expressionist models of tutoring, using instead "a variety of strategies that they can apply with flexibility" (2). She finds conceptions of an "ideal" tutorial problematic, and suggests that tutor-writer rapport, agenda setting, and writer expectations determine whether or not a session is "successful." She suggests that the "tutor can easily be directive, occasionally, as needed, and still keep the writer actively involved in the session" (6).

Despite the aforementioned studies and assertions, the concept of "minimalist tutoring" (Brooks 1) continues to dominate writing centre scholarship.

\section{Tutoring Non-Native Speakers (NNS)}

Writing centres are increasingly directing their attention towards NNS writers. In the early 1990 s, a handful of writing centre theorists began to embrace contrastive rhetoric, the idea that logic and rhetoric are culture-specific, rather than universal (Kaplan, 294). Judith Powers was amongst the first to suggest that traditional collaborative strategies may not be appropriate or effective for NNS students. She notes differences in the educational, rhetorical, and cultural contexts of NNS writers, 
recommending that tutors take a more directive stance and assume the role of "informant" rather than collaborator (41).

At about the same time, Thonus ("Tutors as Teachers") examined the tutorial conference vis-à-vis then-current trends in NNS writing pedagogy. Like Powers, she urges writing centres to be more cognizant of cultural differences in writing strategies and to expand their methodological bases to include approaches specific to NNS writers. After a decade of research, Thonus ("What are the Differences?") revisited the same issue with a varied and exhaustive analysis of writing centre "talk," exploring the differences in tutor interactions between first and second-language writers. She says that tutors "must be willing to relinquish the orthodoxy of the collaborative frame and permit more realistic and appropriate 'contact zones' for tutorials with NNSs" (240).

NNS issues are difficult for tutors to deal with because they so often involve requests for (and sessions that devolve into) editing. Cogie, Strain, and Lorinskas, influenced by Powers, propose specific strategies for NNS error correction, a means of circumventing the "proofreading trap" (14). This issue of the "proofreading trap" is later revisited by Myers. She further develops the notion that tutors must work to develop a greater understanding of second language learning processes and a keen knowledge of the pedagogical grammar of English as a second language.

In a more recent, intensive analysis of 18 tutorial sessions, Blau, Hall and Sparks ("Guilt-Free") find the Socratic method of tutoring to be ineffective with NNS writers. Like Thonus, they situate their study in the literature on cultural writing differences, especially Kaplan. They advocate a tutoring approach that is more directive and even more form-focused when dealing with NNS students, hoping to alleviate the "guilt" some 
tutors feel about "going line by line through portions of a paper" (43). Writing centres, they say, are becoming "de facto centres for NNS education," and need to extend their focus and scholarship to include second language acquisition and contrastive rhetoric (43).

Instances in which tutors stray from their basic ideals and act in a directive manner have been documented and shown to be pedagogically effective. Outside of the work of Blau, Hall, and Sparks, there are practically no empirical studies illustrating a similar phenomenon with the order of concerns. A small number of writing centre theorists influenced by Mina Shaughnessy (who emphasized grammar, but not in the "skill and drill" sense; she advocated direct explication of the concepts of grammar) have acknowledged that sentence-level errors can sometimes be a priority, especially in an open admissions environment. However, few theorists have dared to suggest that socalled "lower order" concerns may occasionally be deserved of "higher" status.

\section{On the Whole}

Ultimately, the writing centre community does appear to be joined by common theoretical bases, bound not only by what we are but also what we are not. The roles of the tutor are well defined, but "the issue of how context constrains and even prevents the fulfillment of these roles is not adequately treated" (Thonus "Triangulation" 60).

Double binds - relative to directiveness, the order of concerns, and role(s) of the tutor - pose a threat to our comfortable, holistic writing centre orthodoxy. I say "comfortable" because it feels right to adhere to the aforementioned philosophy; so right, in fact, that it can be difficult for tutors to accept alternatives as worthwhile or compelling. All the literature about writing centres, when combined and internalized, can 
have a synergistic effect on writing centie personnel, causing our theory to form a kind of dogmatic ideology, a "comfort zone" to which tutors can retreat in the face of the aforementioned double binds. Through reflection and direct observation, this study will explore these contradictions, concentrating primarily on the voices of the tutors who experience them. 


\section{CHAPTER THREE}

\section{METHODOLOGY}

\section{Chapter Overview}

This chapter is divided into four sections; an introduction/general overview, and three sections based on each of the three methods of research used in the study. The first of these deals with the reflective e-mail interviews with tutors and writing centre directors, the second describes the direct session observations, and the third explains the survey and the rationale behind it.

\section{$\underline{\text { Introduction }}$}

The study utilized a mixed-method approach, employing both qualitative and quantitative means of empirical inquiry. I used multiple triangulation (Denzin, The Research Act), combining different research methodologies and theoretical perspectives to examine the same writing centre phenomena. Data was gathered via reflective e-mail interviews (from tutors and writing centre directors), an online survey, and direct observation of tutorial sessions. By employing multiple theories, methods, and empirical materials, I hoped to overcome some of the inherent limitations and biases of single method, single-observer, single-theory studies. The data from each part of the study was collected and analyzed separately, but the overall results were viewed collectively in order to explore the larger meaning. In order to further contextualize the results, supplementary information, including training materials, how-to tutoring manuals, and various writing centre mission statements, was also taken into account. All data was studied and evaluated solely by myself. 
All data was viewed holistically with North's "idea" of a writing centre in mind. My research questions were the focus of my analysis:

1) How does the theoretical "idea" of a writing centre manifest itself in day-to-day writing centre reality?

2) How - and how frequently - do tutoring sessions devolve into situations that contradict our shared philosophy as tutors?

3) How bound are we by our shared ideals?

4) Is it ever appropriate to use methods/techniques that are at odds with the very foundation of our approach?

5) Is there a disparity between the "idea" and the reality of a writing centre?

My particular interest was in how tutors respond when the basic tenets of writing centre philosophy are threatened or compromised by their session. Ultimately, my goal was to explore interpersonal relationships within the writing centre and note how - if at all - the writing centre theory/philosophy advanced by the literature manifests itself in writing centre reality. I relied most heavily on tutor reflections, in order to include their voices into the larger discourse about writing centres.

\section{$\underline{\text { Reflections }}$}

The tutor/director reflections served as the primary source of data in this study and provided a larger context for the direct session observations. The reflections were responses, generally lengthy and coherent, to open-ended interview questions. As a whole, they provided me with a collection of thoughtful ruminations about tutoring and writing centres. Through the reflections, I hoped to observe the "dialectic between the systemic and subjective-partisan views" (Engeström and Miettinen, 10) in the writing 
centre. Capturing the voices of the tutors themselves was of paramount importance. I intended for their voices (as made manifest in the reflections) to function "less as standalone texts and more as voices and utterances in ongoing dialogues within and between collective activity systems under investigation" (Engeström and Miettinen, 10).

\section{Participants}

The study included 30 participants, 23 tutors and seven writing centre directors from various North American universities in both the United States and Canada. The participants - selected primarily on the basis of their diversity - were recruited from 21 different writing centres to ensure a more representative sample. By perusing a variety of writing centre websites, I was able to recruit an extremely diverse group of tutors from a multitude of different institutional settings.

I chose to focus exclusively on four-year universities in the United States and Canada. The schools from which the participating tutors were recruited are widely dispersed geographically, located on the East coast, West coast, and everywhere in between, in both urban and rural areas. There are both public and private institutions. Some schools emphasize engineering and the sciences, while others focus on liberal arts. I also looked closely at the demographics of the student body for each school, including ethnicity, age, and socioeconomic characteristics. This concerted effort to make my sample culturally and geographically diverse allowed me access to wide-ranging perspectives from an assortment of tutors working in different institutional and cultural contexts. The reflections of these tutors more accurately represent the lived experience of the entire writing centre community than would a snapshot case study of one particular space. 
Of the participating tutors, six taught at Canadian universities, and 17 taught at American universities. There were 15 females and eight males. Of these tutors, three are represented by data from a pilot project in 2005 (see Appendix E for old interview questions). The central focus of that project was largely the same as this study; however, the questions have been slightly modified for this project, as my empirical aspirations and theoretical bases have evolved and expanded since then. Regardless, the data provided by those three tutors remains extremely relevant. Of the participating directors, three directed Canadian writing centres, and four directed writing centres in the United States. There were five females and two males.

Four of the participating tutors were non-native speakers of English. In terms of educational attainment, the tutors ranged from $4^{\text {th }}$-year undergraduate students to fullfledged professors with Ph. Ds. Most commonly, they were graduate students. All tutors fit Stephen's North's criteria for being "involved" with writing centres, having worked there for well over 100 hours ("Idea" 433). In fact, most tutors had taught in the centre for over 500 hours. All are experienced pedagogues who show evidence of what Schön would call "a kind of knowing-in-practice" (viii). These are not neophyte tutors; some even have a background in writing research and theory. They were chosen precisely for their experience, because they were already well acquainted with writing centre theory and practice. I wanted to find out if, when, and why experienced tutors would break their own self-imposed rules. A tutor cannot break the "rules" without first knowing what they are. As such, I needed my participants to be eminently familiar with writing centre philosophy. While the implications of this study may extend to trainees, direct observation of novice tutors and training exercises is outside the scope of my research. 


\section{Procedure/Data Collection}

This portion of the research (the reflections) was strictly qualitative. 23 practiced tutors were interviewed via e-mail about their experiences in the writing centre. In addition, seven writing centre directors were also interviewed regarding the training of writing centre employees and the instructional philosophies espoused at their particular centre. These were not formal "interviews" per se; my questions were framed as openended vehicles for reflection. Tutors, especially, were encouraged to take time to reflect on their craft. I wanted them to think before they wrote; immediate feedback was not a concern. Both tutors and directors were given ample time (at least 10 days) to respond to the questions, and were encouraged to write as much as they wanted.

The interview questions (see Appendices B \& C) were framed with Dewey's old axiom in mind, "A question well put is half answered" (108). This was not a matter of baiting or leading the participants, but simply identifying the problem at hand.

Education theorists Copeland and Birmingham cite problem identification as a "critical attribute" of reflective practice: "A reflective teacher is not only aware of these problems, but he or she also takes care to define them in an explicit, conscious way" (350). Questions thus dealt with tutoring style, philosophical bases for tutoring, expectations, and various precipitating factors that determine the nature and outcome of tutorial sessions (see Appendix A). Each question was meant to spur tutors to reflect upon a particular aspect of their experiences. All data was gathered through "reflection-onaction" (Schön The Reflective Practitioner); that is, tutors reflected on previous occurrences in tutorial sessions. Reflections also functioned as "reflection-for-action" (McAlphine et. al. Educational Research), in that they occurred "prior to instruction" and 
may inform future sessions. All reflections occurred outside the "event," the writing centre tutorial session.

The e-mail correspondence was studied and evaluated exclusively by myself. The interview data was subjected to an open-ended but thorough analysis, with an eye towards identifying typical and atypical ideas and practices amongst the participants. Throughout my inductive scrutiny of the data, there was a great deal of what Schön ("The Reflective Practitioner") would call "problem reframing," as my theoretical bases were constantly modified in response to emerging patterns and regularities. Ultimately, my analyses became - to borrow from Clifford Geertz - my "own constructions of other people's constructions of what they are up to" (qtd. in Smart, 9).

\section{Direct Observation of Sessions}

With the director's permission, I personally observed and analyzed five different tutorial sessions in the Carleton University Academic Writing Centre. Sessions were also tape-recorded for posterity and further analysis.

\section{Setting}

Data was collected on location in the Carleton University Academic Writing Centre/Writing Tutorial Service (WTS). The WTS offers free, one-on-one tutorials to any Carleton student who wants advice on the writing of university papers. It is run by the School of Linguistics and Applied Language Studies and staffed by graduate student tutors from a variety of disciplines at Carleton University. The WTS, as far as writing centres go, is more or less archetypal in its mission and function, espousing a studentcentered, process-based approach to writing instruction: 
By giving you suggestions on how to develop your writing skills, the goal of the WTS is to help you develop your writing as well as support you in the process of completing your written academic assignments. [We can] help you to examine and improve your overall writing process, as well as introduce you to helpful tools and strategies for academic writing at different stages of the process [...] We will not do your writing for you, but we will help you to discover principles for effective writing and hone writing strategies that work for you. ("Frequently Asked Questions")

Clearly, the WTS encourages student agency, placing ownership of the text in the hands of the student. Note that this mission statement refers specifically to "your" overall writing process, rather than the writing process. Word choice and phrasing also point towards student-centeredness: "develop," "help you learn," "help you examine and improve." As is the case with many writing centres, they have appropriated North's dictum: "Remember that we are here to help you become a better writer, not to ensure that you produce a perfect paper" ("What to Expect").

\section{Participants}

Participants in this portion of the study were five undergraduate students and their respective tutors. Of the five tutees, two were NNS writers. All tutors were graduate students, two from the School of Linguistics and Applied Language Studies and three from the English Department. 


\section{Procedure/Data Collection}

Five tutorial sessions were observed and analyzed. All WTS sessions are scheduled to be 50-minutes in length, though some ended sooner than that. I took extensive, specific notes on each of the sessions as they occurred. Following common practice in observation research (Bishop 79-80), the data was analyzed and reassessed on an ongoing basis. I focused on commonalities and disparities as they recurred from observation to observation. Sessions were taped with a microcassette recorder, and explored more thoroughly in a post-session analysis. All aspects of the social relationship between tutor and student were studied. Particular attention was paid to pedagogical methods that seemed to contradict writing centre philosophy.

Sessions were viewed holistically in terms of recurrent themes, rather through a word-by-word micro-level analysis. My intent was not to identify static, objective truths, but to explore the fluidity of the student-tutor dynamic as it naturally occurs, to investigate organic rather than "inert" (Whitehead Aims) actions. This was a situated analysis at the macro-level; I looked at broader rhetorical implications of the words and phrases used by the tutors and students, observing the tutorial sessions in context. The importance of context cannot be overstated, especially with respect to writing centres, where tutor-student interaction is dependent on so many different variables. To ignore this larger context only detracts from the results, and, in the words of Bakhtin, "leads to perfunctorines and excessive abstractness, distorts the historicity of the research, and weakens the link between language and life" (63). 
As with any ethnographic observation, there are inherent limitations. There is always the possibility that participants may behave differently simply because they are being observed; this effect of the observer on the observed is generally referred to as the "Hawthorne Effect" (Adair). There may be an element of performance, however slight. Observed reality can never be actual reality; these observations, like any others, offer not a slice-of-life, but an observed slice-of-life. That said, I made a concerted effort to preserve the normal flow and dynamic of the session; the tape recorder was carefully placed in an unobtrusive location, and I did not speak or participate at all. I made it very clear to students and tutors that I was not there to evaluate them, and that there was no "right" or "wrong" way to behave. I found that both parties seemed to forget about my presence as the session progressed. Admittedly, there is no way to know this for sure, but these students and tutors had goals and objectives to reach; at some point, they had to work to achieve them, irrespective of whether or not someone was watching.

\section{$\underline{\text { Survey }}$}

\section{Participants}

210 respondents completed an online Likert Scale (1-5) survey (see Appendix D), indicating the frequency or infrequency of particular scenarios in their tutorial sessions and their comfort level with said scenarios. Participants were both tutors and writing centre directors, recruited through the WCENTER listserv.

\section{Procedure/Data Collection}

This was the only quantitative portion of the research. The survey (See Appendix D) consisted of 35 questions, generated entirely by myself, based on my own intimate understanding of the subject matter. Each item in the Likert Scale sought to measure 
attitudes in terms of level of agreement/disagreement with a target statement about tutoring. Survey data was analyzed quantitatively using basic descriptive statistics, and variables were weighed against one another via cross tabulation.

I chose to forego the traditional Likert scale with its 4 ordered response levels in favor of a five-point Likert Scale with a "neutral" option. The reason for this is simple: I am uneasy about forcing people to take a side. Sometimes a person just doesn't feel strongly about an issue. Making the participants choose - forcing them out of their comfort zone - would undoubtedly provide richer data, but at what cost? Removing the neutral option could conceivably skew the results, since people who may not have strong opinions on a particular issue must agree or disagree. I acknowledge that there are certain limitations to using a 5-point scale. The neutral option offers tutors an out, a way to avoid the question altogether. Sometimes people need a little pressure to make a choice; without the impetus to choose, participants may play it safe, choosing "neutral" and remaining middle-of-the-road without giving a statement enough consideration. However, I am less concerned with overly cautious responses than I am with forcing a genuinely undecided participant to make a decision. Given the nature of my research, I don't want to drive tutors towards or away from a particular ideology.

Another atypical characteristic of my Likert Scale is the use of certain indefinite temporal words, like "sometimes" (questions 5, 20, 24), "often" (30, 32), and "usually" (6), as well as non-specific words like "most" $(9,13)$ and a number of modals like "should" $(1,2,18)$. Such words are generally avoided in Likert scales, but I needed to avoid absolutes. Absolutes can provoke negative answers, since people may have a kneejerk reaction to disagree with any unequivocal, all encompassing statement. More 
importantly, there are no absolutes $i_{\imath}$ tutorial sessions, so the aforementioned words help me to refer to things that may occur, even if they do not occur all the time. Our philosophy is relevant most of the time; I want to look at the exceptions, which is difficult to do without these words. 


\section{CHAPTER FOUR RESULTS AND DISCUSSION}

\section{Chapter Overview}

This chapter is separated into six sections, five of which are based on notable trends in the reflection and observation data vis-à-vis my research questions. The first section examines the shared ideals of tutors, including philosophical bases, methods, and pedagogical styles; the second deals with conflicting goals and expectations that lead to double binds; the third section explores the directive/non-directive continuum; the fourth looks at the order of concerns and priorities in a tutorial session; the fifth section summarizes how tutors define themselves in a holistic sense, and the last section presents the raw survey data.

The data proved extremely rich, offering a myriad of possibilities for analysis. The tutor reflections alone resulted in over 90 pages of single-spaced text. This corpus was not a lengthy transcription of casual spoken conversations, but rather 90 pages of coherent, erudite thoughts about tutoring. As such, the tutor reflections became the primary source of data. I quote liberally from the tutors; collectively, their cogent articulations say more about writing centre reality than one researcher ever could. Direct quotations are anonymous. Gender pronouns in reference to the tutors (he, she, his, her) are randomized, and may not reflect the gender of the actual participant. Tutors and directors are numbered consecutively based on the order of their appearance in the paper. In the interest of maintaining the integrity of their responses, all the original punctuation and spelling is used when tutors and directors are quoted directly. Use of parentheses, underlining, boldface, etc. is theirs unless otherwise indicated. 
Very similar thematic strands emerged from all the inquiry strategies. Common words, phrasings, and recurrent conceptual themes were immediately evident. Often, the strategies espoused by the tutors in the reflections would manifest themselves in the observed sessions, and would be further substantiated by one or more survey answers. Data from the director reflections and direct session observations is sometimes used to support the themes. This data is directly referenced far less than the tutor data, in the interest of giving tutors a voice in the professional conversation.

Schön says, "The situations of practice are not problems to be solved, but problematic situations characterized by uncertainty, disorder, and indeterminancy" (16). In writing centre practice - where student and tutor exigencies diverge and mutate at ever-increasing speed - this is precisely the case. The following results illuminate tutors' means of functioning in sessions full of ambiguity and value conflict.

\section{Shared Ideals}

\section{“Producing Better Writers"}

The tutors had internalized a very similar set of "rules" - the basic tenets of tutoring in a writing centre - that they used to guide their sessions. They knew the philosophical backbone of their practice, understood their mission as tutors, and enthusiastically voiced these beliefs:

We deal with the student's writing holistically. (Tutor 1)

My role is to help the students become better writers, including helping them to be better editors of their own work, increasing their awareness of any weaknesses they possess and of ways to 
mitigate these weaknesses, aiding them in becoming better readers of their assignments and of their own work, and strengthening their abilities as critical thinkers. (Tutor 2)

A good tutor is someone who listens to and addresses students' needs, is non-directive in approach, knowledgeable, and empathetic. (Tutor 3)

The responses reveal a devoted adherence to student-centered pedagogy and a process-oriented approach that immediately evokes North's "idea" of a writing centre. North's seminal ideas - sometimes even his very words - appear frequently in the tutor reflections. Though no tutor references him directly, all enthusiastically champion his ideas and, at times, seem to appropriate his language. The most immediately evident example of this was found in the tutors' holistic priorities:

Work with the writer more than the essay [...] you're looking at the longrange picture and not trying to do everything at once. (Tutor 4)

While the immediate responsibility is to amend a paper, the overall domineering role is to help make better writers. (Tutor 5)

Like North, their philosophical forebear, the tutors are focused on the writer, rather than the individual piece of writing. They embrace the notion of writing as a larger process, one that goes beyond a single paper with a single grade. As Tutor 4 explicitly says, tutors always have the "long-range picture" in mind.

Directors generally shared tutors' student-driven, process-based motives: 
[Our role is] to help students develop their abilities as writers; to work towards the development of a culture of writing. (Director 1)

Our fundamental objective is to put the needs of students first [and] help the student see their current activity (writing, revising, editing, etc) as part of a longer process. (Director 2)

We nurture writers rather than writing. (Director 3)

Not surprisingly, nearly all participants were on the same page, and saw the tutor's job as "producing better writers."

\section{Tutor Talk}

As expected, the tutors are big proponents of "talk" in the writing centre. Virtually every tutor either implicitly or explicitly identified open dialogue - both speaking and listening - as the heart and soul of a tutorial session:

My guiding philosophy is to help students become better writers through dialogue and open-ended questions [...] to help students see their strengths as writers. (Tutor 6)

My role as a tutor is to engage the student in a conversation about the process of writing $[\ldots]$ TALK to the writer - ask what the writer is trying to 'do' as they write. (Tutor 7)

A tutor talks first, reads second, then asks and asks and asks and then chooses what to do and where to focus. (Tutor 4)

My type of learning process is to talk things out. (Tutor 8) 
A good tutor is someone who listens to the student, determines where the student is in his or her writing, and engages the student in the kind of interrogative questions that experienced writers ask themselves [...] My role as a tutor is to help the student engage in a conversation about what they've written or are going to write [...] the writer knows how they've written and why. (Tutor 9)

Good sessions involve a continuous dialogue between the tutor and the student. (Tutor 2)

The tutors and directors repeatedly stress the importance of "making the student comfortable" through "talk" and "exchange of ideas." During a particularly long lull in one of the observed sessions, a tutor even said to a student, "I need you to talk; it's kind of what we do here" (Observed Session 2). These statements hearken back to North's notion of "talk" as the "essence of the writing centre method" (443). Indeed, these tutors saw "talk" as the backbone of their work as tutors. This was especially evident through Tutor 9's telling comment, "Students who are unwilling to talk are probably the most difficult to work with."

\section{Student Centeredness}

All the tutors advocated a holistic, facilitative approach to learning and believed devoutly in sessions that empower the writer:

I want them to feel more confident about themselves, like writing is something that involves their own agency. (Tutor 4) 
Each session should move the student writer towards greater independence. (Tutor 1)

Ultimately, the best thing I can do for someone is to help them gain control over their writing, to be more autonomous. (Tutor 10)

A good tutor is more of a facilitator than an instructor [...] our mission is for them to learn how to be independent. I want to equip students with skills necessary to become a good writer. (Tutor 11)

Good tutors allow students to take ownership of their work and will not dictate changes to them without making sure that these are the changes that they are comfortable with. (Tutor 3)

My role is to facilitate active engagement between tutees and their writing, giving tutees the tools to engage in their own writing process [...] In other words, tutees should not be dependent on the tutor to "correct" their assignments for them, but should be actively involved in the session and be able to take what they have learned and use it in future assignments. (Tutor 12)

I'm not really there to impart knowledge but to draw it out of the student [...] Good tutors can forfeit their own sense of authority; they can surrender their assumptions about the students they work with and allow the writers to individuate themselves. (Tutor 9) 
They understood their role as that of a "facilitator", and spoke extensively of the "needs" of each individual student. They expressed a desire to increase writer "autonomy", and actively encouraged student agency in their sessions.

The Directors were more apt to speak about facilitating not just writers, but writing "communities." Director 2 sees "tutors as guides helping to bring students into a community of practice." Director 1 concurs, stating her that centre's mission is "to facilitate the growth of individual writers and to foster strong academic and creative writing communities."

\section{"Social Keennèss"}

To the participants in this study, a "good" tutor is defined not only by pedagogy and procedure, but also by the interpersonal dynamic he/she creates. Results indicate that tutors are extremely cognizant of the socio-emotional aspect of their tutorial sessions - of how a student feels - and generally try to establish a comfortable, positive atmosphere for learning. A writing tutorial session is a special kind of dialogue, one that "demands vulnerability and a certain intimacy that is rare in educational situations" (Tutor 13). Tutors were mindful of this distinctive context; their answers revealed an acute sensitivity to the psychological and emotional state of the student: "I'm there for reassurance when they want to change something and for guidance when they are overwhelmed by the task [...] I try to make the writing centre as inviting as I can" (Tutor 9). Tutors took great care to "be nice", put their students "at ease," and asserted that their most important job was to establish a "real human relationship" (Tutor 13) with the tutee. Interaction on a personal, non-academic level was invariably touted as the most important aspect of a 
session. Tutor 5 describes the elusive "social keenness" tutors use to make this connection:

My role as a tutor is twofold: an academic guide and a motivating friend [...] A good tutor must also possess social keenness [...] he/she will immediately make the student feel 'at home' in the writing centre [...] and offer some friendly words of encouragement, always affirming he/she is on the right track. In doing so, a good tutor encourages students to take personal pride in amending their papers [...] Sessions where students feel removed or uncomfortable frequently end poorly.

Evidence of this "social keenness" appeared throughout the reflections; both tutors and directors repeatedly emphasize the need to be a "people person" (Tutor 11), to be "friendly," "patient," and "supportive," to "reassure" students, to "identify" with them and to show "empathy" when they are distressed. Director 1 speaks to this:

I've learned over the years [...] that the strongest writers do not necessarily make the best tutors. Someone who has to struggle more with their writing can have more empathy. In screening potential new tutors, we look not only for good writing skills but also for strong interpersonal and intercultural skills [...] Remember that conferencing with other students is a human encounter. It's important to be a good writer and to know how to talk with other writers, but don't forget that you're talking/working with a person just like yourself.

Continuous "positive affirmation" (Tutor 12) was also an unmistakable trend, advocated regularly in the reflective data and put into practice by the all the observed 
tutors. Tutors saw that students often came to she writing centre frustrated, already at "wit's end," having lost the capacity to be objective about their own written output: "Writers often feel vulnerable, too close to their own effort [...] to see the validity of what they have written" (Tutor 14). Many tutors look, first and foremost, for the positives in a paper, hoping to point out something the student does well:

I always, always try to find at least one good thing to praise in a paper. Many students seem to be self-deprecating or defensive when they come down here, seemingly feeling compelled to make excuses for their writing or their writing abilities. And, really, it's never nearly as bad as they seem to make it out to be; so to improve their overall confidence (because I think a big factor in being able to write well is believing you can), I always try to tell them what they do well before I tell them what could be made better. (Tutor 15)

The tutors placed a great deal of importance on student confidence. Tutor 6 says, "tutors should not $[\ldots]$ say anything that would diminish the students' confidence in their ability to write." Director 4 concurs, warning that "instructors must be supportive and understanding of how emotional students often become when having their writing scrutinized, how frustrated and demoralized they may from being told that they are 'lousy writers."”

Indeed, in every single session I observed, tutors spent a large portion of the session reassuring apprehensive students. Consider this excerpt from observed session 2; the student and tutor are discussing a biology paper, which dealt with a caterpillar's larval stages of development into a butterfly (italics mine): 
Student: So I put this here?

Tutor: What are you trying...to say with it... with those words?

Student (tentatively): I'm...not sure about...the order...

Tutor (reads aloud): well...you say 'the epidermis begins to form a new cuticle'...right?

Student: Yes.

Tutor: Does it happen before...before the other stuff?

Student: After the release... of the proteins...that happens first...

Tutor: So, yeah...I think this is really good, that you put this here...

Directors generally steered tutors away from making evaluative judgments, but the observed tutors were perfectly willing to proffer statements like "this is a good idea," or, "I like what you did here" to reassure hesitant students. Feedback of this ilk was given throughout the observed sessions:

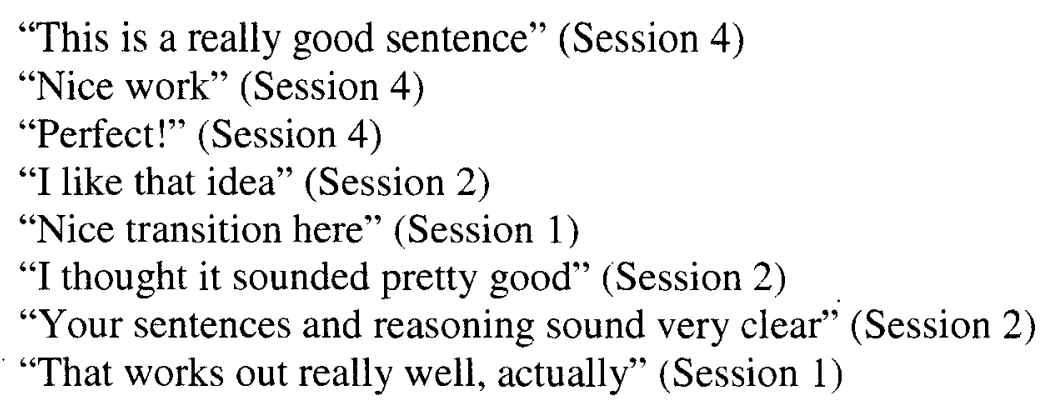

Indeed, as Tutor 3 puts it, "many times, one's job as a tutor is to simply assure the student that they are not the worst writer in the world."

Tutors would also attempt to reassure students by identifying with their plight. Tutor 13 says it is important for a tutor to also "be a writer" to develop a sympathetic common ground with tutees. Many neophyte writers seem to believe that more advanced writers have a "gift" for spontaneous creation, that cohesive, beautifully eloquent prose simply emanate from their brains and pens at will. Tutors, whose understanding of the writing process is typically "based on extensive personal experience" (Tutor 16), shared stories of their own writing troubles in order to debunk this myth and reassure struggling tutees: 
I also try and recount times where I have struggled with my own writing experience. I hope this helps the student to see me more as a peer and not as another part of the establishment. (Tutor 3)

I sometimes openly draw on my own personal experiences with academic writing [...] I talk about the psychology of the writing process, like the anxiety and ego-involvement - e.g. the impulse to start without an outline or sense of direction (it allays anxiety to get something, anything, on the screen), the desire to keep in material that doesn't belong just because you spent time reading about it or laying out the sentences, feeling injured by a professor's slighting comments. I think it is often cathartic or reassuring for students to hear that all writers go through these things. (Tutor 16)

Tutors identifying with students was also a trend in the observed sessions, as in the following excerpt from session 2 :

Student: I just don't know what say in the conclusion...

Tutor: Yeah...they're hard.

Student: I mean, the paper, it...it flows now...it's...good...I think...but how do I end it? I never know what to say...it never seems good enough...

Tutor: Good enough?

Student: You know, like... something that people would want to read...I want to end with something really...I don't know...profound. Tutor (nodding): Yeah...yeah, I totally have the same problem ... sometimes, you just want end on a high note, really wow your reader with something.

Student: Yes...yours was probably good, though...mine are always sort of...they just don't sound right...

Tutor: Conclusions are hard for everybody...I think... at least they're for me...

Student: Oh...umm...so how can I do it?

Tutor: Well, what I do with conclusions is re-read my introduction. And I ask myself what my point was with the paper...

Student: OK... 
Tutor: So what was your point?

These examples are emblematic of the participants - the tutors in this study made a concerted effort to identify with their students.

The positive feedback itself was sometimes borne out of tutors' own struggles with writing:

I think the reason I use positive affirmation so often derives from an experience I had as a tutee during my undergrad. When using another writing centre, the tutor was very critical of my work and did not mention any good points concerning my writing. I left the writing centre feeling less confident about my paper than before I arrived. And also less motivated to complete it! (Tutor 12)

The purpose of identifying with tutees was not only to diminish their anxiety, but also to create tutor-student solidarity. Tutor 5 explains:

I like to say [...] 'off the record, you should do this' or 'this is something that almost all teachers eat up'. Saying such phrases not only highlights important advice, but also strengthens the relationship between the tutor and the student, working together to 'beat the system.'

This solidarity is very important to some tutors; it may explain why some are more inclined to refer to themselves as "peer" than "teacher," and why they may hesitate to be directive, lest they be construed as omniscient dispensers of knowledge, perpetuating the "infallible identity many students associate with writing center tutors" (Tutor 5). 
Ultimately, it was enormously important to the tutors that the students leave a session feeling better, not only about their writing, but also about themselves (italics mine):

My goal for sessions is to have students leave the room with A) a clear understanding of precisely what they most need to do to improve their writing, and B) the belief that they are able to do it. (Tutor 2)

I hope that students leave the writing centre thinking more positively about writing. (Tutor 9)

Tutors were quite conscious of how their words made tutees feel, and wanted to be sure that tutees left a session "encouraged, not demoralized" (Tutor 14).

On the whole, the "social keenness" advocated by the tutors is important because it speaks to the very essence of the tutoring process. Most tutors sought to create a kind of "comfort zone" for their students, a place where people are more important than the writing they create. In keeping with this notion, Director 5 comments, "we always introduce ourselves with first names and create a comfortable, friendly atmosphere." The tutors in this study went beyond looking merely at "writers" and "writing"; they took great care to cater to the psychological and emotional state of their students. There was a nurturing aspect to the tutoring dynamic that manifested itself in both the reflections and the session observations. The imperative to create a comfortable "connection" with the student was verbalized in some capacity by every single tutor who participated. A . university can be an intimidating place for students of all ages. Tutors in this study strived to make the writing centre a place of comfort, a safe haven, someplace like "home." 


\section{Survey Data - Shared Ideals}

Evidence of a shared philosophy did present itself. Out of 210 respondents, $86 \%$ (182) chose either "agree" or "strongly agree" in response to question 1, "Tutors should be facilitators rather than directors." $78 \%$ (162) of respondents agreed or strongly agreed that, "Means are as important as ends in a tutorial session" (Q9) indicating an awareness of writing-as-process. 92\% of respondents (196) chose either "agree" or "strongly agree" for question 6, "A tutor should be student-centered in his/her instruction." And for question 32, "It is of paramount importance to facilitate learning at the student's point of need," $90 \%$ of respondents (189) either agreed or strongly agreed. This was not at all surprising, as most writing centres endorse a facilitative, student-centered pedagogy. This was also consistent with the qualitative findings, where tutors also claimed to make student "needs" a priority.

\section{Synopsis}

The answers seem to indicate that the tutors have a very clear conception of what it means to tutor in a university writing centre. They use largely the same phrasings to describe their philosophies and objectives, and appear to hold similar beliefs and assumptions about the tutoring process. The very words they use seem to indicate a common terminology. Some of these words almost appear to have been written by North himself. Throughout the results, the ideas espoused by the tutors were consistent with (and possibly informed by) writing centre theory and scholarship, so much so that, at times, the answers bordered on formulaic regurgitation of writing centre doctrine.

In fact, some tutors said that writing centre philosophy had influenced and shaped the way they think about writing: 
I think that my own feelings about writing have been shaped by the writing centre's philosophy. I feel that I have taken on the writing centre's philosophy. (Tutor 12)

Before I worked at the writing centre, I never asked anyone to look over my writing. I thought that 'good writing' doesn't need a second opinion. Thankfully, through my work at the writing centre, I have come to see that this concept of writing is not only self-righteous but lacks progress. Although I didn't truly internalize collaboration until a few months after I began working as a writing consultant, I feel that I have grown to share the philosophy of the writing centre. (Tutor 17)

Results indicate that there is indeed something of a unified writing centre philosophy, and the tutors in this study embody it. This was more or less what I expected from experienced writing centre personnel. Having been immersed in writing centre practice (and, it seems, theory), these tutors and directors understand their philosophical bases for tutoring, advocating a fairly consistent set of pedagogical ideals.

\section{Contradictions, Divergent Expectations, and Double Binds}

The reflective interview data also highlighted the contradictions that invariably plague writing centre tutors. All of the tutors, not surprisingly, experienced double binds on a regular basis. Most could be attributed to divergent student/tutor expectations from a session. More often than not, a tutor's goal of "producing better writing" was not shared by the student. Contradictory demands left tutors in a "need state" (Engeström, Learning 16), torn between upholding writing centre philosophy and catering to the 
student's wants/needs, conflicted in such a way that meeting one demaıd would categorically prevent them from fulfilling another.

\section{Learning to write and writing to learn}

Interestingly, tutors tend to adhere to an "expressivist" (Britton; Elbow) philosophy of writing, perhaps because so many come from English departments. In the last section, it was noted that tutors want to empower writers, and encourage students to be autonomous and to take "ownership" of their writing. Writing, to these tutors, belongs to the student, and is more than just a tool; it is an extension of an individual. This type of writing is what James Britton termed "expressive" - that is, writing that is closest to the self (106).

It follows, then, that tutors see writing as a learning process, a way to build and integrate knowledge, a means of self-discovery:

We are role players in the construction of knowledge. (Tutor 1)

We stress writing to learn, writing as critical thinking, which is how I tend to see my own writing processes. Writing isn't the end product, but my way of synthesizing ideas and developing new ones. (Tutor 18)

Teaching writing is a balance between direction and self-discovery. (Tutor 3)

Indeed, many tutors emphasize what Tutor 18 called "writing to learn." When people write to learn, they use writing as a mode of learning, they write in order to learn what they have to say. Writing becomes a vehicle for thinking, a process that leads to "a discovery of structure and coherence - a structure that grows out of the material instead 
of being imposed upon it" (Elbow 286). Students who write to learn are, in the words of James Britton, "shaping at the point of utterance" (1.10), figuring out what they have to say by writing it down. This is a decidedly constructivist view of writing, in that students basically write themselves into being; by framing whatever they are looking at in particular ways, they are creating a world. Through writing to learn, tutors hope that the writer can bring order to confusion, give shape to intuition, and provoke unexpected connections. Gillespie and Lerner, as if to promote this notion, devote an entire section of their tutoring manual to "co-constructing meaning" (114).

Unfortunately, students seldom shared this conception of the tutor's role:

Students generally are very focused on the assignments at hand, and do not see themselves as writers in the larger sense [...] I feel like the purpose of writing, its benefits and its challenge, get lost in the particulars of what each student needs to do to get an A. (Tutor 9)

These students are "learning to write," rather than writing to learn. They are using writing in a utilitarian way, as a means to an end, a way to "get things done" (Britton, 109). Writing, to them, is a tool for action, rather than a process of self-discovery.

Tutors are generally writers (in some capacity), and typically write to learnmore often than not, that is their writing process. Consequently, they try to teach that process to students. Their tutoring is infused with it. Tutors, as writers, sometimes expect students to display a greater commitment to writing than they do. Consider North's assertion: "Writers come looking for us because, more often than not, they are genuinely, deeply engaged with their material, anxious to wrestle it into the best form they can" (443). This is a rather bold assertion, likely to provoke skepticism from anyone 
who has taught writing. North himself debunked this myth, worried that tutors who took it at face value would "blame themselves (or, just as problematically, the writers they work with) when their tutorials don't seem to be so unproblematically driven ("Revisiting", 11). This clash between writing to learn and learning to write appeared throughout the reflections; many tutors lament sessions in which students are unwilling to “engage." Tutor 9's above comment was but one example.

Not all students write to learn. It is more likely that students write in order "to be finished with writing; to have their writing finished" (North, "Revisiting" 10). As Tutor 9's revealing example shows, students are motivated by grades, and all the demands associated with obtaining a high grade - mechanical correctness, thorough documentation - these are the things that instructors ask for, and consequently, what students most often want to focus on. It is not surprising that tutors like Tutor 9 feel that the "purpose" of writing is "lost" on these students. Students are more often learning to write than writing to learn, creating a double bind for the tutor.

\section{Process and Product}

Process and product clash on a regular basis in the writing centre. Students often do not value the same things that tutors and directors do. The holistic goals of tutors tend to clash with the immediacy of student needs, forcing tutors to choose between their student centeredness (meeting student needs) and their process-based writing philosophy: Students only want their immediate concerns to be met. (Tutor 14)

Because students enter the writing centre unknowledgeable about what English professors look for in writing, their goals are not quite the same as 
mine. They typically look for simple things: grammar, clarity, and transitions. (Tutor 19)

Students frequently want the quick fix or the dry cleaning service - dirty paper in on Friday, cleaned and pressed Monday morning. (Tutor 13) Tutors who wish to produce better writers in the long-term sense are met with students who are interested only in one paper and the grade it receives. Tutors approach writing as something organic and constantly changing; therefore, when students only want to focus on external text characteristics, a double bind inevitably results.

\section{Change}

Change - as North asserts - is the very sole of process-based writing. Writing is never "done," but is constantly going somewhere and doing something. A process approach to writing stresses multiple drafts and constant revision. North applies this notion to the writing centre, and suggests that a successful tutorial session be measured in terms of "changes in the writer":

Rather than being fearful of disturbing the 'ritual' of composing, they [tutors] observe it and are charged to change it: to interfere, to get in the way, to participate in ways that will leave the ritual itself forever altered.

Writing centres expect and sometimes even "demand" this change in their tutee's writing: We demand that students show that they've progressed on an assignment before returning for a second or third appointment. (Director 4) Needless to say, some writers have no desire to change, leading to a double bind for tutors. Tutor 9 identifies her most difficult students as those "who see their first drafts as 
too valuable." While tutors saw a student's paper as something ongoing, their students rarely did.

Conversely, there were students who so focused on change that the writing-asprocess mentality itself proved binding. Consider this anecdote:

Just the other day, a writer came in with a very interesting assignment [...] the writer had been working on the narrative for 2 weeks, and she was concerned that her drafts had not undergone any sort of change since she initially sat down to write. Her goal for the session was to make some sort of noticeable changes to the paper. [However,] I thought what she had written fit perfectly together. She said her teacher was a big advocate on progress in writing, and she was worried that her writing lacked progress. I offered that perhaps discussing writing strategy and philosophy can bring about progress, even if it isn't put into writing. She agreed with this, but still wanted to change the paper. Conceding somewhat, I helped her brainstorm some ideas on how she could reorganize her thoughts, if she were to change them [...] She figured out how to make 'progress.' And I got to pretend that she didn't end up changing her beautiful writing for the sake of a professor. (Tutor 17)

In this situation, the student is concerned that her paper has not changed enough, placing Tutor 17 in a double bind, caught between trying to preserve the "beautiful writing" of the student and meeting the process-driven requirements of the professor. The student sees her paper as only one part of an ongoing writing process; therefore, it must continue to evolve. In this example, the emphasis on change in the writing process is narrowly 
interpreted as a necessity for tangible difference. Certainly, every paper can be improved upon, but change for its own sake is hardly what North - or any other process-minded pedagogue - had in mind. Overly rigid adherence to overly simplified notions of process can lead to these problems, perhaps even, in a worst-case scenario, causing tutors and students to alter writing in ways that may actually detract from it. Tutors should take heed; sometimes our theoretical assumptions, even those that seem all but unassailable (process: good) are stood on their head by real-life circumstances.

\section{Collaboration (or lack thereof) and defensive rhetoric}

Tutors cited as their most trying sessions those involving insistent or pushy students who want the tutor to do all the work. Some students expected tutors to edit/proofread and/or to take a much more directive role. "These writers" says Tutor 20 , “don't understand the writing centre philosophy of collaborative learning, and I end up feeling more like a grader than I do a tutor." Tutors and directors still lament the lingering "fix-it shop" perception that North railed against over 20 years ago:

Some of them [students] some in with the wrong idea of a writing center thinking we write papers for people. (Tutor 11)

There are always students who want a 'quick fix' and are more reticent to work on the paper during the consultation as that is deemed to be the consultant's job. Oftentimes, students will come wanting a complete proofreading service $[\ldots]$ this is a time that my philosophy has been compromised. (Tutor 3)

We do not edit or re-write. We are not a remedial centre. (Director 5) 
I $[\ldots]$ have this one student who comes in and $[\ldots]$ wants me to write the paper for him (at least tell him what to write and map it all out), and then is always dissatisfied with the sessions. I have to continually talk to myself when working with such students, and tell myself that what this student wants is not what I should be doing. (Tutor 8)

Faculty and TAs sometimes tell me something to this effect: 'after I get the first batch of papers in, I'll send some people over." Which tells me that they see our role as remedial. (Director 2)

Some of them [students] come in expecting a quick fix, and some even go so far as to try to manipulate the tutors into giving them an easy way out. This is disappointing, but all you can do is say, 'no, we' re doing it my way - according to the official procedure - and if you don't do the work, you get kicked out and your spot is given to someone else.' (Tutor 21) This lingering misconception of a tutor's role has existed as long as writing centres have. The data indicates that tutors felt most conflicted, most compromised, and most threatened by students who wanted editing or proofreading. Following with this idea, almost all directors spoke out against editing and proofreading, and several were concerned that their centres were still construed as exclusive to "remedial" learners. When faced with these sorts of double binds, some tutors resort to a defensive mindset:

In cases where it was, 'Dude, proofread this for me' $[\ldots]$ well, then it's a question of boundaries. I don't do that. You can't make me. It's 
disrespectful of you to insist on it after I told you it's not part of my work and not what I can do for you. (Tutor 4)

This example perfectly illustrates tutors' tendency to retreat into the ideology when their values are threatened. Tutors, when forced to deal with "a question of boundaries," may just resort to "this is not what we do," further demonstrating our capacity to define ourselves in starkly negative terms.

A number of other tutors report being similarly annoyed by student requests for proofreading/editing (italics are mine):

Being big on collaboration, I am insulted when a student asks to drop off a paper for me to edit for him/her. (Tutor 17)

I had one of the most horrific sessions with a freshman male student who kept pushing his paper in front of me and telling me to write out what I had just talked about with him [...] I honestly think that is what these students need to hear, that I cannot write their papers for them, that $[\ldots]$ this is their assignment. (Tutor 8)

Occasionally, I have a student who just wants a proofreading service. That expectation absolutely has to be combated. (Tutor 16) It's certainly understandable why tutors feel compromised; the aforementioned circumstances would frustrate anyone with a holistic, facilitative mindset. However, the words they use are very revealing. They are "insulted" by requests for editing; proofreading and authoritative instruction are described as "horrific" experiences that must be "combated." The word "combated" is a particularly interesting choice, as it 
implies vigorous, alilitant opposition, which flies in the face of our student-centeredness, and seems completely antithetical to the supportive reassurance that most tutors purport to give.

It is not so striking that these students did not want to proofread and spoon-feed ideas, but the extent to which they were apoplectic about it gives us pause. Perhaps our holistic approach has been so internalized that tutors sometimes have difficulty accepting other methods as appropriate or effective. Process pedagogy can have an evangelical air about it, so much so that anyone with an outcomes-based mindset is vilified. As these examples show, some tutors are not only uncomfortable but outwardly irritated when pushed to do something outside their own prescribed boundaries.

\section{Survey Data - Double Binds}

Most of the survey questions dealing directly with double binds received very scattered answers. Also, a number of questions showed somewhat polarized, bi-modal disagreement. This may be a product of the confusing nature of the double binds themselves. There were a few interesting statistics that seemed to indicate divergent expectations. Only $7 \%$ of respondents (16) agreed with the statement, "Most students are eager to write" (Q12), which immediately brings to mind the many reflections in which tutors lamented students unwilling to "engage." Only $7 \%$ (15) agreed that, "A successful session ends with a high grade for the student" (Q7). Also, only $22 \%$ agreed that, "The student and tutor usually have similar expectations from a session" (Q5). Further evidence of double binds became evident through cross tabulations. There was a significant correlation between question 13, "There are times when my philosophy has been threatened by a session," and question 23 , "I sometimes get 
defensive when asked to proofread something," with a P value of .001 and 16 degreses of freedom. This tells us that the very tutors who feel "threatened" are prone to react defensively when asked to proofread. This is not so surprising a correlation, but it points towards even greater likelihood that particularly intense double binds involving proofreading do occur with these respondents.

Question 13 also correlates significantly $(\mathrm{P}=.049,16 \mathrm{df})$ with question 25 , "The most crucial aspect of a tutorial session may be grammatical instruction" and question 27 , "It is important that all sentences in a paper be grammatically correct" ( $\mathrm{P}=.031,16 \mathrm{df})$. These statistics reflect the "threat" of lower-order concerns to writing centre philosophy. Keeping with this theme, there is a strong - though not significant - relationship between question 13 and question 28, "Students often want to address grammar issues first."

A significant correlation $(P=.003,16 \mathrm{df})$ was found between question 20 , "I can become frustrated with my student's inability to answer my questions," and question 35 , "I do most of the talking in a typical session." This correlation also makes sense, as those who become "frustrated" with the Socratic norm in the writing centre are more apt to do the talking.

\section{Synopsis}

In practice, new tutors often experience cognitive dissonance as a conflict of loyalties. They feel pulled, on one hand, by their loyalty to their fellow students and, on the other hand, by loyalty to the academic system that has rewarded them and whose values they have internalized. (Trimbur 23)

Double binds are an unavoidable aspect of a tutor's job. The problem, essentially, is that their holistic objectives tend to clash with the pragmatic goals of the 
students. Most students want to write - if they want to at all - only to complete the task, to be finished with writing and to move on to more relevant (to them) concerns. As teachers of writing, tutors have to balance their idealistic philosophy (producing better writers) with the goals of the student (earning a high grade on that particular assignment). Tutors sometimes have a difficult time mediating between these conflicting interests, as evidenced by their tendency to get defensive when asked to proofread. As the next sections will show, double binds are most pervasive with respect to directiveness and the order of concerns.

\section{Directive Tutoring}

Results indicate that directive tutoring, which is completely antithetical to most writing centre philosophy, occurs in practice, despite its lack of theoretical support. While virtually all the tutors engaged in some kind of directive tutoring, they differed in their levels of directiveness, in their reasons for being directive, and in the extent to which they were comfortable with it. They used different strategies when acting directively, and relied on these strategies with varying degrees of frequency.

\section{Double binds precipitating directive tutoring}

In some ways, the tutors' role creates inherent contradictions that lead to a double bind and, subsequently, the tutor acting in a more directive manner. All of the tutors occasionally felt pressure to be directive. The institutional setting often exacerbated these pressures, increasing the frequency and intensity of double binds, causing some students to feel stifled by their own theory. They were, as they saw it, working in an environment that would invariably test their boundaries: 
We have a diverse student body; the students who visit us often are the products of an insufficient and dysfunctional public school system. Consequently, I feel the need to compensate for gaps in learning. (Tutor 1)

Open admissions along with a high percentage of ESL students create many challenges. It is challenging to communicate clearly and effectively with students who do not have strong communication skills. (Tutor 6) These tutors feel tension within their activity system, as their tutoring approach - based on "talk" - is compromised when students are unable to communicate effectively. The tutors recognize that they work in a unique atmosphere, one that can intensify double binds and hasten the need to be adaptive.

In these and other situations, students felt the inherent drawbacks to a Socratic, non-directive approach. Tutor 1 recalls, "I have students who think I must not know much because I keep asking questions." Tutor 5 points out that "the nondirective approach to tutoring places on heavy emphasis on the student realizing his/her weak points and strong points in a paper." This is an excellent point; there are students who simply do not know the answers to our questions. Certainly, with carefully worded queries, we can lead most of them in the right direction, but there will always be students who lack the knowledge they need to realize their own shortcomings.

This contradiction was even more pronounced with NNS students. Most of the tutors argued that NNS writers come to writing centre with a completely different and infinitely more complex set of issues than native speakers. 
ESL conferences are very difficult for me because the process seems to go against what I've been trained to do. With ESL students, much of the work is more directive. (Tutor 9)

This was a real problem at [institution omitted]. All the tutors there, including myself, were criticized for being too directive with ESL students, and yet we were not given any answers as to how not to be directive. (Tutor 8)

I think the situations I find most difficult involve ESL students who would like explicit instruction as to why a certain sentence or error is wrong. It is frustrating for me, because if I simply correct the sentence for them, they are often not gaining anything from that experience. If correction of that sort continues, I wonder to what extent their paper becomes my paper? (Tutor 12)

These tutors all felt that their ideals were especially conflicted when tutoring an NNS student; after all, many come to the writing centre only for explicit instruction.

Tutor 8's statement, in particular, illustrates how confining rigid, unbending rules are for a tutor. Therein lies the double bind; tutors are torn between being directive and going against writing centre ideals, thus (in Tutor 8's case) alienating the director of their writing centre, or adhering to writing centre philosophy and alienating the student, who would prefer that the tutor take a more active role in the session.

\section{Tutorial role conflict}


Directly related to the ongoing directive/non-directive debate is the role tutors should play in a tutorial session. Do tutors consider themselves "peers"? How many consider themselves "teachers"? Is there a middle ground? What do students expect? What are the implications of each role? Writing centre theorists have grappled with these questions for years.

The data in this study provides no single conception of what a tutor's role should be. Tutors saw themselves in a number of different contexts, and in an incredibly varied array of roles. Some tutors believed devoutly that they were acting as "peers":

My primary role is being a peer. As someone's peer, I do things with a writer that good friends would do - I listen to him/her. I ask questions. I take an active interest in the project at hand. I care about how he/she feels at the end of our session. (Tutor 17)

A tutor's role is comparable to that of a peer, not a teacher. [A tutor] is not meant to be an authority figure. (Tutor 19)

Tutor 19 not only defines herself as a "peer", but also contrasts herself against the role of "teacher." This was not uncommon in the reflections. However, while most tutors hesitated to label themselves as an "expert" with the "answers," many felt just as uncomfortable acting as an outright "peer":

I see myself as more of a teacher than a peer tutor for the simple reason that I have experience and expertise in writing. I think it's important to 'own' the knowledge you have even if where you work has a peer tutoring model. (Tutor 10) 
Generally speaking, tutors with more experience were less likely to refer to themselves as "peers." Like the majority of tutors who saw themselves as more of a "teacher," Tutor 10 cites her knowledge and experience as the primary reason for her slightly elevated status. These tutors operate under the assumption that they must know more than the students about writing; otherwise, why would students come to them for help?

The self-assured authority garnered from experience extended beyond the peer/teacher question. In most cases, those who were classroom teachers as well as tutors felt more comfortable being directive. Invariably, those with any classroom teaching experience outside the writing centre had fewer qualms about directive tutoring; to them, there was a time and a place to be more explicit and authoritative. Perhaps this is because they could view the tutorial session from two perspectives, as both a tutor and a classroom instructor.

Tutor perceptions of their own role varied in accordance with not only experience, but also age and educational attainment. Age was perhaps the most influential factor:

I'm a young looking tutor; at age 23 , I look like I might be 18 or 19 - with this being the case, I can see how the students I tutor might resent me for correcting them when I don't look like I should know any more than they do. (Tutor 7)

As many of the younger students in the study were precisely those most attached to the notion of "peer," how old they were - or, perhaps, how old they looked - may have determined their self-identity as a tutor. This relates to being directive; students who are younger saw younger students as their peers, and were reticent to tell older students what 
to do. And, indeed, those who were older sad a hard time identifying with younger students. Notions of peer were inextricably tied to the age of the tutor.

As a whole, most tutors, irrespective of their perception of their role, were reticent to act as outright authority figures. A few reject the designation "tutor" on this basis:

I much prefer the term 'collaborator' to tutor, which automatically sets up a 'the scholar is bigger, the student is lesser" mindset. (Tutor 18)

Tutors - insofar as they downplay their position of presumed superiority - sometimes even regard their students as co-teachers:

I try to develop the student as a better and more enthusiastic writer, but I also hope that I will leave the session as a better tutor and writer as well. (Tutor 5)

My goal (and maybe it is a selfish one) is not only to help the writer to the greatest extent; it is also to maximize my benefit from the session. (Tutor 17)

However, as Stephen Brookfield explains, students may not share this perspective:

To students who have made great sacrifices to attend an educational activity, a teacher's attempts to deconstruct her authority through avowals of how she'll learn more from the students than they will from her rings of false modesty. Students know teachers have particular expertise, experience, skill, and knowledge. To pretend otherwise is to insult students' intelligence and to create a tone of mistrust from the outset. (6) 
Tutors often define themselves as students' intellectual equals, but this self-definition alone does not have the power to change students' perceptions of their superior status. Some tutors were aware of this, and saw rigid adherence to the Socratic method as implicitly condescending: "Don't make students guess at answers that you know, just waiting around for them [...] They know they're being patronized" (Tutor 5).

Consider the continuation of Tutor 8 's story: "The director of the writing lab in which I now work is honest with us ... and we know that, say, writing on a student's paper (which is a reason for termination in many writing labs) is going to happen at times." Her words are very telling; she considers the more flexible approach, the one that allows for the occasional directive action (like writing on a student's paper), to be more "honest." Indeed, many tutors felt that the imperative to be non-directive was, at times, transparently disingenuous.

\section{"Leading questions" and "delayed directive tutoring"}

Some participants - both tutors and directors - felt that it was unrealistic to expect tutors to act exclusively in a non-directive manner. Tutor 5 assumes this perspective, noting that even the hallowed Socratic method can be tacitly imbued with directiveness. The way a tutor listens and answers, he says, may be as important as the questions asked:

I fear I sometimes fall into what I call 'nondirective directive tutoring.' Perhaps I ask 'Why did you transition from paragraph C into paragraph D in that way?' [...] If the student responds to what I expect is correct, I proceed. However, when any answer deviates from my preconceived correct answer, I immediately offer my suggestion and move on. Asking the question, I realized, gave me the false impression that I was 
'nondirectively' tutoring the student when in reality all I was doing was delayed directive tutoring.

In this example, Tutor 5 had already chosen a path for the writer, and his questions were only meant to lead the writer to that one place. Indeed, questions themselves can be directive, especially if the tutor - as was the case with Tutor 5 - is really only looking for one thing. If a tutor already has a single, narrowly construed answer in mind, then the questions he/she asks cease to be open-ended. While Tutor 5 may not have been acting directive in an overt manner, the student was clearly not determining the direction of their session.

Instances of "delayed directive tutoring" were occasionally evident in the tutor reflections. Consider Tutor 1's technique for dealing with unresponsive students:

I redirect the questions for one instance, guiding the student to a response that is on target, so they can see the fruits of the thought process. Once they experience one 'a-ha', they are usually more invested in the peer tutoring process.

Tutor 1 has fallen into the very trap Tutor 5 talks about; when she "redirect[s]" her queries, she anticipates a particular response, one that is "on target". By "guiding" the student towards these ends, she is engaging in delayed directive tutoring. She believes, ironically, that this series of questions allows the student to experience a "light bulb" moment ("a-ha"), when, in fact, the idea was actually hers. One might argue that the student is seeing the fruits of her thought process, rather than his/her own.

I use these examples not to illustrate the effectiveness or ineffectiveness of delayed directive tutoring as an approach, but to show the extent to which directiveness 
can be covertly embedded in the context of a session. As such, tutors may be acting directively far more often than we believe. Many tutors in the study asked what they called "leading questions" in their sessions, but to "redirect" a student through a series of loaded questions is itself a means of being directive. A session can easily devolve into an exercise in delayed directive tutoring; this must be considered, particularly by those who define themselves unambiguously as non-directive peers. Indeed, one of the more difficult things for teachers to learn is that "the sincerity of their intention does not guarantee the purity of their practice" (Brookfield 1).

\section{Being directive}

Directive tutoring, which is generally discouraged by writing centre philosophy, occurred with startling frequency throughout this study. Some tutors were directive to a greater degree than others; a surprising number of tutors reluctantly admitted to having done little more than "line-editing" in a session. All of the tutors reflected upon occasions when they had been directive:

Directiveness can help a lot in moving from one dialect to another as well as from one language to another. [...] I'm a very open-ended non-directive tutor and teacher. But there are times when someone appreciates being told what is wrong or what would make it [the writing] stronger. There is a place for directiveness. There is. And I trust my instinct more than I trust any formula on that. (Tutor 4)

I suppose my philosophy is to use non-directive tutoring as much as possible, but not to withhold it from situations where it should be used. (Tutor 8) 
All students are different and each of them requires a certain way of work. Some students are independent and ready to cooperate, but others need you to give them exact directions. (Tutor 11)

Sometimes the idea that the student always has to be in control can be restrictive. If there is something that I want to address, or a point in the paper that would be really useful for the student to look at, that Socratic conversational ideal becomes really false. I think students can benefit from a little direction once in a while. (Tutor 9)

Should a tutor give the student a thesis statement or re-write an opening paragraph? Well, the dogmatic answer would be 'no,' but there are times when such an act can set the student off in the right direction. (Tutor 13) Clearly, the tutors are acting in a directive manner, and with few qualms or reservations about it. They saw this not as a faux pas, a blunder, or an accident, but as a legitimate instructional strategy.

Tutor 15 noted that, "I tend to make more suggestions than I do offer leading questions." This was a recurrent theme in the direct session observations, where the observed tutors made direct suggestions quite frequently. Most of these suggestions were made at the sentence level. Tutors gave students words or phrases to deal with issues of parallelism or simply told them where a comma should be placed. This almost never occurred without an explanation of the grammatical concept, but students seldom seemed interested in the explanations. Most suggestions at the global level had to do 
with organization. Tutors would advocate moving paragraphs from one part of an essay to another or suggest placing the thesis statement in a more prominent location.

\section{Why are tutors directive?}

Tutors were directive for a number of reasons, the two most common of which were: 1) to help struggling students, and 2) to model examples. Some students were directive simply to "save" the student from getting too frazzled:

I have been more directive with students who are visibly distressed/agitated by their work, and I tend to give them a few concrete answers to their questions rather than letting them feel it out by themselves. (Tutor 3)

Sometimes, you have to give the gift of a word, if a client is really struggling. (Tutor 18)

When I sense that a student is totally overwhelmed and if I have a fairly good sense of what the assignment requires, I may suggest an organization and then work with the student to put her ideas in that structure. (Tutor 14) When sitting face-to-face with an anxious, perplexed student, many tutors had difficulty suppressing their natural inclination to be proactive. Even those who had relegated directive tutoring to special circumstances, saving it to use only as a "last resort," needed to be authoritative when other options had been exhausted.

This was the case throughout the observed tutorial sessions. Interestingly, the tutors did more talking than the students in these sessions. When a student had trouble 
responding to a tutor's question, the tension in the dead air was positively palpable, as if the double bind itself had enveloped them:

Tutor: So is that...that part, is that the same thing you said on the last page?

$<$ rather long silence >

Tutor: I mean, when you talked about...motivation? Can you explain that in a different way?

$<$ even longer silence $>$

Student (confused and hesitant): I...umm...

Tutor: You just want to talk about the same things, but in a different way. Student: Like...how?

Tutor: The motivation thing...OK, can you just explain it to me? And don't worry about writing it...

$<$ yet another long silence $>$

Tutor: You could say “The struggle between"...yes? And lead into your discussion like that? (Session 2)

In this session, the tutor and student struggle with the Socratic norm. The tutor relieves the double bind by offering a phrase, and then asks another question. This is a directive measure meant to help/engage the student. The tutor is clearly trying to avoid being explicit, and the session becomes very uncomfortable because of it.

Another recurrent rationale for being directive was modeling examples. Tutor 8 claims to "always offer my ideas... as examples." Tutor 1 concurs, saying "the tutor should model strategies for a similar assignment subject." Showing a student how to do something was not necessarily perceived as doing the work for him/her. Consider this excerpt from Session 1 (italics are mine):

Student: I'm sort of...that's re-stating my thesis, but should I... sum up...the three paragraphs?

Tutor: Yeah, especially since you'll be adding examples of what encompasses the genre.

Student: And I can put that in my conclusion?

Tutor: Yeah...this [points] is how you want to conclude this sort of paper, right?

Student: Yes...so I should go back and talk about the same things? 
Tutor: You can do that...you can just say 'this is what's going on here, and this is why this thing I discussed exemplifies it, this is how they relate to each other, this is why it's relevant... and this is why my argument makes sense...

Student: So that's... summing it up? I talk about the same things? Tutor: Well, that basically is summing up your thesis...you want to show that you have actually presented an argument, and because of that argument, your thesis works...otherwise you're just...saying things...

The italicized words represent a common modeling strategy; tutors would remove specifics from their examples and simply model structure. In this case, the tutor uses the demonstrative pronoun "this" to distance his comments from the actual context of the paper. This allows him to be directive without suggesting words and phrases specific to the assignment. Tutors, as writers themselves, felt that students could learn by their example, but did not want to be construed as giving the student's concrete ideas.

Tutors justified this strategy based on context and student need, as Tutor 8 does in this passage:

What is my goal in anything I do with that student, including writing on his/her paper? If it's because I want them to sound like me, then I had better get out of the writing lab ... but if it is to show them how a sentence works, for example, perhaps it's not such a horrendous act.

This example is emblematic of a recurrent theme in the data: the tutors would never admit to acting in a nondirective manner without explaining why the nonstandard strategy was necessary. The tutors had clearly given these issues a great deal of thought. They repeatedly called attention to their familiarity with writing centre philosophy in their answer, as if to acknowledge that they do, in fact, know the conventions, and would never have contradicted them without good reason. Directive tutoring was deemed acceptable and even necessary...in certain situations. 


\section{NNS/advanced students}

Directive tutoring was most commonly advocated for NNS students:

In some cases, like working with an ESL student, a directive approach might be useful more often than not; asking guiding questions and hoping to lead the student to a realization about her/his writing might simply be a waste of thirty minutes. (Tutor 15)

In ESL conferences, I sort of accept that I need to be more directive and recognize that these students are at a different level of learning in terms of the straight mechanics of the language. (Tutor 9)

I have ended up simply line-editing papers for students before $[\ldots]$ This is not at all what our writing centre, or any others I suspect, is for. Most often, this happens when I'm working with a student for whom English is their second language. I' $m$ not a linguist or a teacher of second language acquisition, meaning that the most I can make of a problem I see in writing is only that it exists. I can fix it, but I'm usually not able to explain why it was wrong. (Tutor 3)

I specialize in tutoring non-native speakers (NNS) of English. With many of this population, it is unreasonable to expect them to come up with 'better' or 'clearer' ways of saying things on their own [...] I will provide collocations, turns of phrase for this group, if I think it is necessary. Is it editing? Is it unfair? Is it unempowering? I guess that if I thought so, I wouldn't do it. (Tutor 14) 
In these cases, the tutors seem to be acting upon thei i notion that NNS writers simply need to be approached differently. It may not be realistic to expect students to come up with answers they simply do not have.

Directive tutoring was also commonly used for more advanced students In situations where I am working with students with high skill levels, I might be more explanatory and use sophisticated language, both of which, I think, are discouraged in the basic philosophy. (Tutor 6)

It was thought by the participating tutors that advanced students might appreciate some critical suggestions and explanations. More accomplished writers, they said, might even find the Socratic method condescendingly daft.

\section{Guilty of being directive?}

It bears mentioning that the tutors consistently felt the need to justify their methods. Some even seemed to feel "guilty" about using certain strategies, especially those that were overly directive. And sometimes, as we saw earlier, they took things a step further and became defensive and contentious. This may indicate that our philosophy is becoming too binding.

Tutor 1 reflects, "Sometimes, I write on the student's work. This does not happen often, and I stop immediately." This is a very telling statement. Writing on work is considered a directive action, and tutors-in-training are generally taught to avoid it. Indeed, Director 5 plainly states, "They should not write on the client's papers." In her statement, Tutor 1 reluctantly admits that she does, at times, break from the ideology. What is especially interesting is her immediate retreat; she rationalizes this action as something that rarely occurs, as if to say, "I didn't mean it! Honestly, this almost never 
happens." She is clearly treading lightly here, lest she be perceived as someone who violates non-directive writing centre philosophy.

There was also evidence of backpedaling due to possible guilt in the session observations. In observed session 2, the tutor makes a direct suggestion: "You might want to say 'after the release of the cuticle,"' then pauses and thinks a moment. Quickly, she adds "but not those exact words." This behavior is strikingly similar to that of Tutor 1 ; once she realizes she has been directive - something that may be perceived as a methodological faux pas - she becomes tentative about her initial inclinations.

Many other tutors expressed a similar discomfort with their own actions:

Sometimes I do more correcting than I theoretically think I should. (Tutor 2)

I end up doing more proofreading and correction-without-explanation than I am really comfortable with. (Tutor 16)

There are times when I think I have been too directive, too immersed in the student's paper. I take it to heart and try to rein myself in the next time. (Tutor 14)

All these tutors' actions are responses based on context, but each realizes that the theory does not leave room for them. Clearly, they accept the philosophy that informs tutoring, but a tinge of guilt appears when they tout that philosophy (as they did in the reflections) and then do something else, something that seems to directly contradict it. The regret that appears after the fact illustrates just how deeply our ideals run. 
Other researchers have noted that some tutors experience guilt when using nonstandard approaches. Blau, Hall, and Sparks assert that, "going against practice seems to be the cause of guilt and frustration" (23). Petit notes that some tutors "felt guilty about the temptation to stray outside of those bounds and take an authoritarian voice" (118). The remorse exhibited by these tutors, then, is not altogether atypical. These tutors are clearly cognizant of the hold writing centre theory has on image.

\section{Survey Data - Directive Tutoring}

The statistics in this category were striking. Out of 211 respondents, 91\% (192) agreed or strongly agreed with question 15 , "In some situations, it is necessary to be directive with a student." Only five respondents saw fit to disagree. This overwhelmingly pro-directive stance supports the tutor reflections, where all the tutors had been directive to varying degrees. However, curiously, 74\% (155) chose "agree" or "strongly agree" for question 16, "I try to avoid explicitly telling a student what to do," and, as mentioned, $86 \%$ (182) agreed or strongly agreed that, "Tutors should be facilitators rather than directors." These answers point to possible double binds for some tutors, as those who avoid being explicit recognize that in "some situations," it is "necessary."

In terms of being more specifically directive, $85 \%$ of respondents (179) sometimes modeled sentences for students (Q19). Somewhat surprisingly, 20\% (42) of respondents would actually "like to be able to proofread assignments" (Q14). This is not a large percentage, but still a much larger number than I expected. Furthermore, question 22, "It can conceivably be appropriate to edit a student's paper," showed unexpectedly polarized results, with respondents both agreeing and disagreeing in large 
numbers. Proofreading and editing - two things which most writing centres go out of their way not to do - are supported by some who took this survey.

Cross tabulations also indicate a significant correlation $(\mathrm{P}=.065,16 \mathrm{df})$ between question 21, "In a tutorial session, I am acting as a peer to my tutees," and question 13, "There are times when I felt like my own tutoring philosophy was threatened by a session." This indicates that perhaps those who embrace the role of "peer" are having difficulty maintaining that role.

\section{Synopsis}

All of the tutors in this study had engaged in some sort of directive tutoring, and virtually all of them agreed there was a time and place to take a directive stance. As selfproclaimed student-centered holists, most tutors found it difficult to maintain an appropriate balance between facilitative scaffolding and authoritative instruction. Students commonly pushed for a tutor to play a more active role in tutorial sessions, leading to double binds. Tutor 22 attempts to describe the almost paradoxical middle ground tutors must assume, "You should let the student's needs guide the session, but not the student. It's important to maintain a certain amount of authority, but you should not be authoritative." The tutors, in their efforts to negotiate that elusive middle ground, often found it necessary to be directive.

\section{The Order of Concerns}

While all the tutors theoretically agree that sentence-level mechanics are a lowerorder concern (LOC), they often make them a priority due to student need. Many tutors, while they are reluctant to focus exclusively on grammar, may be inclined to do so in 
certain situations. As such, lower-order concerns are sometimes addressed first, especially with NNS students.

\section{Familiarity with the order of concerns}

All of the tutors acknowledged a certain priority (or, at least, a "sequence") in sessions. Tutors normally tried to address higher-order concerns (HOC) first; to them, it made little sense to polish the external text characteristics of a paper before the thinking and writing were clear:

In terms of writing concerns, [the priorities are] focus, clarity, logic, organization, development, and then grammar [...] in general, students are more concerned with grammar than content. I explain that editing for something like comma usage before addressing content revisions is like carpeting a house before you put the roof on. (Tutor 6)

I look for higher-order concerns like clarity, organization, ideas/content, and how closely the paper follows the assignment. (Tutor 22)

I tend to work from global to sentence level concerns, as do most of the tutors in our centre. The rationale is simple: it is illogical to invest time (yours and the student's) in perfecting sentences in paragraphs that need significant reorganization. (Tutor 14)

The priority in a session should evolve around what is often referred to as first (higher) order concerns. First order concerns involve the broader, yet more essential parts of a paper, such as a strong thesis, development, smooth transitions, logical structure, and so forth. Second (lower) order 
concerns such as grammar, proper citation, etc, should be addressed afterwards. (Tutor 5)

We try to work by addressing HOCs (content - the rhetorical triangle and organization) first and then moving downwards to LOCs (usage and punctuation, identifying patterns of error). (Tutor 15)

Priorities are higher order concerns of thesis, organization, theme development, transitions, conclusion and where needed, the integration of sources. Least important are grammar and sentence-level issues.

(Tutor 18)

Most tutors recognize HOCs and LOCs, and some even refer to them by name. Tutor 19 even sent a diagram, "The Hierarchy of Concerns," to illustrate her understanding of the concepts. None of these answers were particularly surprising, as tutors are generally trained to adhere to the order of concerns as closely as possible.

However, the sequence was not as hierarchical as I had expected. Many tutors were uncomfortable in labeling any aspect of a session a "priority," and gave much less prescriptive answers:

If by 'priority' you mean 'content then grammar,' I think priority is the wrong word. It's a sequence, not a priority. I see grammar as very important. It just works better to do content first because it often clears up a lot of grammar concerns. (Tutor 4)

Tutor 4 clearly had a conception of higher and lower-order concerns, but was hesitant to label any one aspect of writing as more important than another. This was a common 
response to my interview question regarding "priorities" (see Appendix C); some tutors did not like being pinned down, responding that "all aspects" of writing deserve their attention. Others gave more textbook answers, but they were no less reticent than the others to break from the "sequence."

\section{Changing the order of concerns}

Tutors reiterated the need to adjust and adapt, and saw no problem with addressing the lower-order concerns first, so long as the session dictated it:

In cases where meaning is muddled because of sentence level problems, those become higher order concerns. (Tutor 18)

Sometimes I do just jump into grammar [...] if it's a matter of sitting down and doing grammar to reassure a student $[\ldots]$ or because a student has a lot of shame about grammar and there's things I can do to help, then I absolutely do that. (Tutor 4)

Attention to product, for example, or lessons about grammar or form, were not condoned, but sometimes that is precisely what's required and what frees students from constraints. (Tutor 13)

The order of concerns is not always addressed in this sequence. Students may resist this order [...] I feel it is ineffective to try and help students with aspects of writing they are resistant to discussing $[\ldots]$ or the writing may be so convoluted that clarity becomes a necessity first, before I can establish whether or not there was an intended focus. (Tutor 6) 
I have focused on grammar first in some situations, which in a way goes against writing centre philosophy. (Tutor 23)

The 'no explicit grammar' philosophy at the institutional level can make it [tutoring] difficult because some students really need this [...] We can't elicit knowledge that the student doesn't have. (Tutor 10)

While nearly all tutors theoretically agree that grammar is a lower-order concern, they would often make it a priority, depending on the context of the session. This trend carried into the session observations, where two of the five tutorial sessions I observed dealt almost exclusively with sentence-level mechanics.

\section{Double binds}

Not surprisingly, very few, if any, tutees have any conception of the order of concerns. As such, they typically come to the writing centre for help with sentence-level problems. The order of concerns, then, often precipitated a double bind. The most common of these seemed to occur in the wake of what Gillespie \& Lerner (2004) refer to as the "editor versus tutor contrast" (50):

Everybody knows that students come in expecting you to do work for them, whether it's giving ideas or fixing the grammar. (Tutor 4)

When students wish to learn about commas before content, then the philosophy is compromised. (Tutor 6)

Because many students are enter the writing centre unknowledgeable about what the $[\ldots]$ professors look for in writing, their goals are not quite 
the same as mine. They typically look for simple things: grammar, clarity, transitions. (Tutor 19)

Very often students come in looking for specific help: fixing grammar errors. (Tutor 15)

These statements, of course, relate directly to the tutor's frustration with student requests for proofreading/editing. All tutors felt pressure to address LOCs earlier in a session. Even as the tutors were process-oriented in their approach, students were often outcomesoriented, concerned more with ends than means. In such cases, tutors felt their philosophy was fundamentally at odds with student desires.

Coping with double binds and the order of concerns: How do tutors react?

Faced with a double bind regarding the order of concerns, some tutors try to compromise:

I had a student come in looking for help with grammar (he was a nonnative speaker of English). However, once we looked at his paper, I could see that the major issue was structure [...] What we did in this session was divide the time between structure and sentence-level issues. (Tutor 12)

Sentence level problems can be addressed simultaneously with global concerns. If I notice that a student is having problems with a particular verb tense, that is worth explaining so that the awareness or knowledge can be applied as the essay is revised - so I guess your could say that sentence level concerns that have a scope beyond the particular sentence may get addressed. (Tutor 14) 
Others will place the impetus for choosing between HOCs and LOCs in the hands of the student:

When I see a paper that has both low and high-order concerns, I bring this up and ask the student to choose which concern s/he wants to deal with. (Tutor 8)

The student sets the priorities. What is most important is what they think is most important. (Tutor 3)

I feel that the priority for a session should be whatever the tutee feels is most important to work on. Sometimes, other issues in the writing might come up, but I feel that if students want to concentrate on a specific area of their writing, the session should be focused primarily on that area. (Tutor 12)

Most often, though, tutors make a concerted effort to shift the session's focus towards HOC:

There is always something larger than grammar [...] usually, if I pick out the areas that are the least clear to me, the session ends up getting beyond sentence-level stuff. (Tutor 9)

A lot of times, tutees come into the writing centre wanting only quick grammar checks, but the majority of those times there are more than just grammar problems. I think that it is the tutor's job to point out these other mistakes as well and help the writer work through them. (Tutor 20) 
They [tutees] usually come in wanting to focus on grammar, sentence level issues, and though there are problems, the meaning isn't always impeded. We'll read through the piece together, and if I see organizational or other higher order concerns, I let them know these should also be addressed first [...] because the sentence level errors may be completely different if sections are rearranged, cut, expanded, etc. (Tutor 18)

This was a common trend amongst the participants; most tutors would try to "redirect" the session towards more content-level analysis. When students requested grammar help in the observed sessions, they were not denied outright, but tutors did try to move the session towards HOC:

Tutor: What class is this for?

Student: 1300.

Tutor: ESL 1300?

Student: Yes.

Tutor: And what is your assignment?

Student: It's like...this is just my draft... and so...uh...can you help me to correct some grammar?

Tutor: I can...I just want to get a sense first of what you're being asked to do...like, what's the assignment? (Session 4)

These tutors tried to uphold the order of concerns, even in the face of double binds.

Faced with a decision that forced them to alienate either the student's interests or their own pedagogical philosophy (which, ironically, is supposed to focus on the student), they tried (with varying success) to sway the session towards higher-order concerns.

Some tutors contend that the paper - the writing itself - and not necessarily the student or tutor, should dictate what is addressed first. They refuse to acknowledge that 
there is an order at all; the direction of the session, they say, is determined entirely by the its context:

My priorities are dictated session to session by the student's situation [...] The most useful thing that I can do may in one case be to talk to the student about the demands of the assignment, in another to work on punctuation. Issues are always addressed in accordance with a hierarchy based on need, rather than a fixed series of steps or pre-decided categories. (Tutor 2)

The priority is to facilitate learning at the student's point of need. Sometimes grammar takes precedence. If grammar issues are the student's point of need, I will address grammar. (Tutor 1)

Both of these tutors maintain that issues in a tutorial session are addressed in accordance with student need, not the order of concerns. Of course, it is the tutor's conception of the writing that determines this need. These comments, it seems to me, are a bit disingenuous, since the tutor is still deciding the focus of the session.

\section{Double binds and NNS students}

Gillespie and Lerner, while they do allow for a certain amount of directiveness with non-native speakers (NNS) of English, insist that with regard to NNS writers, "higher-order concerns still come first" (126). Tutors in this study seem to have difficulty maintaining that hierarchy, and thus report feeling particularly conflicted by sessions involving NNS students. Other research has shown that L2 students - who typically come to the writing centre for no other reason than to achieve mechanical correctness - are just as frustrated with the impasse. In a study of L2 learners' 
acculturation into Canadian universities, Cheng, Fox, and Zheng found that L2 students usually cited "proofreading" or "correcting grammar" as their main reason for using a writing centre (14). As such, most found the experience "unsatisfying" and reported that the writing centre "did not help" (14). An L2 participant in their study commented on this: "They just wouldn't help me. I know the thesis [and] the organization [...] is important, but first I have to say what I want to say. I mean I want to write it in correct English first" (14). The evidence in this study and others seems to contradict many of Gillespie and Lerner's so-called "myths" about non-native speakers of English, particularly myth \#3 "NNS writers come to the writing centre to get their grammar checked" (119).

Both of the observed sessions involving an NNS writer began with the student specifically asking for grammar help:

I can't correct some grammar mistake(s)... and I need help to understand some language people use...so, can you help me to correct some grammar?" (Student, Observed Session 4)

I am looking for help with...grammar, clarity... and also...flow. (Student, Observed Session 2)

Tutors, in light of these persistent requests, deviated from the order of concerns most often with NNS students. These students were perceived as "less familiar with the basic mechanics of the language" (Tutor 21). The order of concerns, some tutors said, is simply different for NNS students:

With ESL writers, I concentrate a lot more on grammar than I do with other tutees because I feel like teachers need to be able to understand what 
the writer is trying to say, and ESL grammar can greatly impede that at times [...] I feel like sometimes their grammar takes away from what they are trying to say (even if they have a great paper in terms of focus, unity, coherence, etc.) (Tutor 20)

We have a responsibility to students who are not proficient with the English language. I have ESL students who I see regularly to talk about idiomatic language, irregularities in grammar and syntax, etc. This is why they come in. (Tutor 8)

Indeed, it makes little sense to talk about organization, structure or focus when a paper is nearly unintelligible at the sentence level. Moreover, as the aforementioned research indicates, when tutors fail to meet the expectations of NNS writers, they leave the student feeling unsatisfied with the session. Some tutors took this into account and made lowerorder concerns a priority for NNS students.

\section{Order of concerns and directiveness}

Grammar issues tend to beget directive tutoring. Many students, the tutors found, need help with grammar. However, tutors found it incredibly difficult to teach grammar strictly by asking questions. Some recommend an unapologetically directive approach for teaching grammar:

If there are problems with [sentence-level] expression, correct them the first time, explaining the nature of the error and the correction; [then] try to get them to correct any subsequent occurrence of the problem.

(Tutor 2) 
A greater number of tutors will act in a directive manner in order to teach the "rules" of grammar:

There are times when I have to just lay down the rules of writing, especially for grammar and citations $[\ldots]$ there are times when there is a definite right and wrong way to do things, and by not acknowledging this and letting a tutee go wild an accepted standard, I feel like I am doing them and their teachers a disservice. (Tutor 20)

From time to time if a paper is filled with grammatical errors to the point where it does not make sense, I will take a good chunk of the session addressing grammatical rules. (Tutor 23)

I have used the teaching of rules, for example, comma rules. As rule instruction is prescriptive, it violates WC philosophy. This occurs fairly (hedging) often. (Tutor 1)

Sometimes a clear grammar lesson gives a student a sense of power and control over a piece of writing, and meaning can then be attended to more clearly. (Tutor 13)

I have, at times, proscribed certain idiomatic rules, such as a paragraph should generally not exceed 300 words. I did this for students who I felt needed a concrete explanation for certain aspects of writing. (Tutor 3)

"Rules," it seems, were fair game to tutors. The teaching of rules was an extremely common occurrence across the observed sessions, as in this excerpt from Session 4: 
Tutor (ruads aloud): 'the first-year student in Linguistics'... so this is your, umm...second sentence in your essay. When you say the first-year student, that means your reader should already know who this student is. Student: Oh...

Tutor: The first-year student...so -

Student: you mean I should augment...so this is not just first-year student...

Tutor: well, no, because this is singular, OK?

Student: Yeah.

Tutor: For most singular nouns, you need an article.

Student: Article?

Tutor: Article... 'the' or ' $a$ '

Student: Ah...

Tutor: So you need...for most singular nouns -

Student: it is...umm...

Tutor: You need one or the other...'the' or 'a'...

Student: You mean I use 'the'... the people I know...I use ' $a$ ' and the people don't know...

Tutor: well, using the... in the context of this your essay...in the context of this writing, this is the first mention of this student...so if you say this [points] 'the', I don't know who you're talking about...

Student: Oh...OK...so he should be 'a'...

Tutor: A first-year student.

As this example shows, teaching grammar rules is hardly same thing as rote editing, and was not perceived as such by most tutors. This trend is consistent with the aforementioned trend of tutors modeling "examples," but not providing actual sentences for the student's paper.

\section{Survey Data - The Order of Concerns}

The order of concerns generated very little agreement in the survey. The answers to questions in this category were either very polarized or overly neutral. This probably reflects what a touchy and often dichotomous issue this has become. Many respondents remained undecided about the importance of grammar, and questions that suggested making it a higher-order concern led to bi-modal disagreement. The one exception was question 31, "Students often want to address grammar issues first." $85 \%$ of respondents 
(176) agreed with this statement, which supports the qualitative data from the session observations and tutor reflections. Of course, the aforementioned results from the proofreading and editing questions also relate directly to the order of concerns and tutors' willingness to focus on form.

Cross tabulations indicate a significant relationship $(\mathrm{P}=.006,16 \mathrm{df})$ between Question 4, "I sometimes address sentence-level mechanics first in a tutorial session," and Question 27, "It is important that all sentences in a paper be grammatically correct." Also, there is a significant correlation $(\mathrm{P}=.000,16 \mathrm{df})$ between question 4 and question 33, "There are sessions where all I tend to look at is sentence-level mechanics and word choice." These correlations make sense, and seem to illustrate a consistency among those who took the survey.

\section{Synopsis}

So, to revisit my fourth research question, can we really "produce better writers" by focusing only on form and external features? Is it possible to adhere to our ideals and still be sensitive to the students' needs and expectations? Even when those expectations contradict our very mission statement?

The tutors differed in their willingness to stray from the prescribed order of concerns, but most did so on a regular basis. This deviation occurred with greater frequency when NNS students were the tutees. Depending on the situation, the order of concerns could be established by the tutor, student, the writing, or the context of the session. Most often, it was determined by the tutor, who purported to make these hierarchical decisions with "student need" in mind. Gillespie and Lerner urge tutors "not to give in to the easy inclination to tackle LOCs before HOCs" (121). However, the 
tutors in tilis study do not appear to have taken the "easy" way out; on the contrary, most had given these issues a great deal of thought.

Double binds pertaining to the order of concerns and directive tutoring are inextricably tied to one another. Often, the pressure to be directive went hand-in-hand with a desire to make lower-order concerns a priority. Despite some tutors' attempts to adhere to writing centre philosophy in the face of these recurrent double binds, all found the need to break from it in certain circumstances.

\section{How Do We Define Ourselves? Adaptability and Contextual Response}

\section{"A universe of one"}

Psychiatrist Erik Erikson described each of his patients as a "universe of one" (72). This characterization is quite fitting for writing centre tutorial sessions, where each student brings a uniquely complex set of needs and expectations to the table. Tutor-tutee discourse is, by nature, organic and fluid. Tutors generally cite "adaptability" - to a particular discipline, a particular assignment, to a particular writing or speaking style, and especially to particular student - as the most important trait a tutor can have:

Tutors must be adaptable and open, so that they will respond to the particular needs of the student before them rather than slavishly implementing some arbitrary method or fixed set of priorities. (Tutor 2)

What makes a good tutor [...] is the ability to adjust to every particular student and every particular piece of writing. (Tutor 4)

Given the different, unpredictable condition of the student and his/her paper, I try not to restrict my tutoring style to a single process $[\ldots]$ The 
best tutors are capable of adjusting their tutoring approach under different circumstances. (Tutor 5)

A good tutor needs to understand that having a working philosophy is a good place to start, but that every situation is unique, and simply having know-how is not enough. (Tutor 21)

A good tutor is one who is flexible and able to assist in determining what is best for the writer. The condition of being flexible came to me because $[\ldots]$ there are many roles tutors take on in a writing session [...] these roles can run together, even in a single session [...] a good tutor is able to identify when a role would fit a session best. (Tutor 17)

A good tutor is perceptive in reading a client's needs and adapting their role according to them. (Tutor 18)

The ability of a tutor to "adjust" to a multitude of different situations was enormously important to all the participants. Virtually every tutor in the study used some combination of the words "adaptable" and "flexible" to describe effective tutoring. Several of the tutors specifically referred to using "open-ended questions," and referred to their goals as "dynamic." Others warned about being too "prescriptive" and repeatedly emphasized the need to be flexible in sessions. They took great pride in their own adaptability, tailoring their approaches to each individual student and situation.

Writing centre directors also touted adaptability in their reflections and in the mission statements at their writing centres: 
We provide flexible instruction while working individually with clients, thus responding efficiently and economically to each client's particular problems. (Director 5)

A good tutor understands how to adjust to every situation and how to manage varied concerns and constraints. (Director 6)

Adapt to the student's learning style and situation - this can affect the amount of structure or type of guidance you give a student, how directly or indirectly you phrase things, how much or how little you talk during the session, whether or not you hold a pen or write on a student's paper, etc. (Director 2)

Keeping with this trend of open-endedness, some tutors warn against entering the session with specific objectives in mind:

A tutor doesn't have a pre-set plan. (Tutor 4)

I don't think it's good to come to a session with a pre-conceived goal [...] Approach each session like it's unique, because each tutee and therefore each session is actually unique. (Tutor 10)

The normative statement of 'should' is one that I try to steer clear from. I think that different sessions call for different actions [...] I find sessions free of expectations go far better! (Tutor 17) 
To these tutors, writing centre philosophy was only as useful as each session would allow. In a rhetorical situation as varied and complex as the writing tutorial session, context was deemed to be of paramount importance:

A student's writing should never be examined or evaluated outside of the context, [including] the reason for writing, the classroom/instructor, the subject matter, the writing assignment. (Tutor 7)

Tutor 7's point - to examine writing only in the appropriate context - became particularly salient in light of the direct session observations, where tutors who relied on absolutes to make a point sometimes had the strategy backfire:

Tutor (reads paper aloud): Lost Ark is the quintessential modern adventure film...

Student: Yeah.

Tutor: Wait...is that the Wikipedia?

Student: Yup.

Tutor: Don't cite Wikipedia.

Student (defensive): Our teacher does all the time...

Tutor: OK, but -

Student: ....and she said it's OK...

Tutor: well...generally, try to avoid citing Wikipedia. (Observed Session 1)

In this instance, the tutor, in a knee-jerk attempt to provide a "rule of thumb" in research and citation, has failed to account for the context. Indeed, in most cases, the student would be ill advised to cite Wikipedia, but the instructor - not the tutor - is the audience for this paper. Tutoring is an extraordinarily complex task; as such, tutors were apt to base their questions and suggestions on the particular situation, rather than what is "generally" true. Perhaps because of experiences like the session excerpt, tutors were reticent to endorse any single "correct" approach to pedagogy, any one appropriate way to do things. 
Many of them eschewed absolutes altogether, endorsing a philosophy of tutoring that was downright relativist. The tutors treat each individual tutorial session as its own entity; they shy away from the categorical and unconditional, embracing the liminality of their position:

A good tutor is not a peer or a teacher; s/he is somewhere in between. (Tutor 8)

I see my role as a tutor as a cross between a coach and a teacher. (Tutor 10)

The tutors saw themselves as maintaining an appropriate "balance," not only between roles of peer and teacher, but between all the opposing elements that clash regularly in a writing centre. Directive and non-directive approaches, higher- and lower-order concerns, process and product, writing to learn and learning to write - these dichotomous forces collide (to varying degrees), and manifest themselves in student and tutor expectations, creating double binds for tutors. Tutors operate with a subtle balance, a fluid adaptability, in order to navigate and overcome these double binds.

Despite their overarching shared philosophy, all of the tutors conceded that tutoring is, by nature, an inherently imprecise activity. They all displayed a profound appreciation of the contextual nature of a tutorial session, as if to acknowledge that, ultimately, rules are meant to be broken:

I could come up with a whole list of what I shouldn't do, but in the end, if one of those 'shouldn'ts' works, why not try it? (Tutor 17) 


\section{Experience}

Most tutors claimed that this adaptability was developed over time through the act of tutoring. They placed a great deal of emphasis placed on the lived experience of the writing centre:

I don't think anyone is really prepared until they have tutored ... and the longer a person tutors, the better things are for everyone. (Tutor 8)

I am much more qualified to tutor now that I have spent a year and a half teaching and tutoring, but that qualification comes from on-the-job experience, not training. (Tutor 7)

You can read tons of books, but until you start working and helping different people, you won't feel confident. During our training, we learned about what to in different situations, what to say and not to say, what to do and not to do [...] but I [did not] really get the feel of being a tutor or realize what I was here for until I worked for a while. (Tutor 11)

No training, under any conditions, can truly prepare one for the practical writing centre. (Tutor 19)

Much of what we do at writing centres must be learned through experience, and no amount of training can really supplant that. (Tutor 3) 
It is difficult to prepare a tutor for a tutoring session, because a session is . very 'experiential.' I think that role-playing during the training sessions was probably the most useful activity. (Tutor 12)

Since each student and each session is different, the ability to respond appropriately came through practice. As far as tutors were concerned, it was practical writing centre experience that allowed them to become self-proclaimed paragons of adaptability.

These statements are quite telling; the experience the tutors see as so important seems to reflect a movement from Learning II to Learning III (Engreström, 3). Indeed, their experience led to "a greater flexibility in the premises acquired by the process of Learning II - a freedom from their bondage"(Bateson, as qtd. in Engeström, "Learning" 4). As tutors spent more time in the writing centre and faced these double binds on a regular basis, they examined their own assumptions and learned to, in their words, be more "adaptable." The focus on the tensions led to an eventual recognition of the double binds and the subsequent creation of new activities. The tutors reworked and restructured activities, "learning by expanding" the old into the new (7).

Schön also accounts for this transition:

When the phenomenon at hand eludes the ordinary categories of knowledge-in-practice, presenting itself as unique or unstable, the practitioner may surface and criticize his initial understanding of the phenomenon [and] construct a new description of it. (63)

Seen through the lens of Schön, the tutor's transition from conflicted and confused to adaptable and flexible can be see not as an isolated, one-time occurrence, but an ongoing process of receiving, reflecting upon, and reconstructing knowledge. 
What tutors have learned tirough experience is an ability to face and cope with double binds. No matter how much training they had, tutors did not experience the contradictions and subsequent "need state" until they were fully immersed in the activity system of the tutorial session. Only when faced with double binds in practice were tutors able to learn, grow, and acquire a "knowing-in-action."

\section{The Art of Tutoring}

If it is true that there is an irreducible element of art in professional practice, it is also true that gifted engineers, teachers, scientists, architects, and managers sometimes display artistry in their day-to-day practice. If the art is not invariant, known, and teachable, it appears nonetheless, at least for some individuals, to be learnable. (Schön, 18)

There was an underlying sense of pride in the tutor reflections, a kind of selfsatisfaction with one's ability to make sense of complexity. The ability to respond contextually seemed very personal and even expressive, indicating that perhaps there is an artful element at work:

The best tutors, I suppose, read their tutees and respond appropriately first sensing where they're at, what they need, how to help [...] no single role ever works. Tutoring is relational, and the tutor must play a role in unison with or in response to the tutee's role. (Tutor 13)

Throughout the study, this intangible "social keenness" - the ability to "read" a student and respond in a nurturing, productive way - emerges as a vital component of effective tutoring. This element of art in tutoring was difficult to distill into a set of immutable 
rules or guidelines. Such artful practice was predicated entirely on the uncertain nature of the session itself.

Let us briefly return to the notion of "social keenness;" it was a fascinating trend because it is not something explicitly taught in writing centre training sessions. All of the tutors seem to champion it and possess it, yet no one seems to have learned to be socially keen in their training. Some directors used role-playing of sessions in their training, but these exercises are highly mediated and decontextualized. The ability to react in such a way was not formally learned; rather, the art of social keenness was embedded within the context of each tutorial session. Consider Tutor 17's description:

Matching a client's pace is helpful, especially if you're having trouble conveying your ideas. I may slow down or speed up my speech, keep pretty monotone and reserved or laugh along with a client, etc. I speak in pace with them - the actual language (using terminology that seems within their realm) and physically matching the rhythm of their speech. I have found this soothes nervousness and brings client and tutor to the same level. This mimicking is not something I set out to do or something I'm even very aware of in a session. I think you sometimes can just read people, and get into a groove with them, and both parties understand the other better.

Tutor 17's account of "getting into a groove" with a student was by far the most intricate description of the aforesaid social keenness. Hers can be seen as a sort of improvisational rhetoric, a tacit "knowing-in-action" (Schön). She tutors from moment to moment, simultaneously relying on her theoretical knowledge base and altering it for the 
immediate context. this subtle art of contextual response is, for all practical purposes, the art of tutoring.

Elizabeth Boquet, using the music of Jimi Hendrix as a lens through which to view a tutoring session, describes a similar set of phenomena:

Improvisation [...] is a consequence of expertise, of mastery, and of risk. [It is] a skillful demonstration performed by someone who knows the tones of her instrument, the rhythms of her musical traditions, so well that she can both transgress and exceed them, give herself over to them, play within and against the groove. (76)

The music metaphor fits perfectly here. A tutor, like a musician, needs to acquire a sound knowledge of his/her "instrument" and "traditions" in order to modify them and "riff" within the framework of the tutorial session.

Directors also cite the ability to "read" students - to respond appropriately, creatively, and constructively in a particular context - as a trait of effective tutors:

I think that if you approach tutoring with the 'right' attitude, it results in 'right' action. When it comes to tutoring, there's a zone or a flow state that can be achieved, where you are in tune with the learner and you intuitively (and collaboratively) settle into a way of working together.

\section{(Director 2)}

Tutoring, by this description, to continue with the music metaphor, is simply playing the right notes at the right time, being "in tune with the learner." Some tutors, however, believe that merely being "in tune" is not enough. Once they learn the "song," they improvise, trying new notes, sometimes finding that the new notes sound better than the 
old ones. This improvisation, for some tutors, is the very soul of a tutorial session: "Orthodoxy is the death of imagination, and tutors need to be imaginative, spontaneous, and creative" (Tutor 13).

\section{Raw Survey Data}

The survey received a total of 219 responses, from both tutors and writing centre directors. There were between 206 and 210 responses for each question (tutors did not have to answer every question). Data is reported in terms of question-by-question trends, means, and cross tabulations. The data serves largely as a triangulating measure, primarily to support the qualitative findings from the reflections and session observations. For complete survey results, please refer to Table 1 (p. 108). Table 1 shows the number of responses for each part of each question, plus means, standard deviation (SD), and standard error (SE). The question numbers in the far left hand column (1-35) correspond to the numbered questions in Appendix AABB. The total number of respondents for each question is in the " $n$ " column. I was most interested in the results regarding directiveness and the order of concerns.

As a whole, the survey data reinforces - to varying degrees - the qualitative findings in this study. The tutors and directors who responded are on more or less the same page philosophically, but inconsistencies are apparent. An overwhelming number of respondents seem to embrace the notion of directive tutoring, while the order of concerns proved a polarizing issue.

The most agreed-upon question in the survey was question 17: "The best tutor is one who can adapt to any situation." $93 \%$ of respondents agreed or strongly agreed with 
this notion. In fact, more than half the respondents strongly agreed. This points once again to adaptability as the primary defining trait of an effective tutor.

Table 1 - Survey Data Raw Scores

\begin{tabular}{|c|c|c|c|c|c|c|c|c|c|}
\hline \multirow[b]{2}{*}{ Item \# } & \multicolumn{5}{|c|}{ ITEM ANSWER PROPORTIONS } & \multicolumn{4}{|c|}{$\begin{array}{c}\text { ITEM } \\
\text { DESCRIPTIVES }\end{array}$} \\
\hline & Strong A & Agree & Neutral| & Disagree & Strong D & $\mathbf{n}$ & Mean & SD & SE \\
\hline 1 & 66 & 115 & 26 & 3 & 0 & 210 & 1.838 & 0.686 & 0.047 \\
\hline 2 & 30 & 98 & 60 & 21 & 0 & 209 & 2.344 & 0.847 & 0.059 \\
\hline 3 & 13 & 75 & 85 & 35 & 1 & 209 & 2.694 & 0.839 & 0.058 \\
\hline 4 & 10 & 84 & 28 & 72 & 16 & 210 & 3 & 1.115 & 0.077 \\
\hline 5 & 0 & 46 & 66 & 84 & 13 & 209 & 3.306 & 0.884 & 0.061 \\
\hline 6 & 94 & 101 & 13 & 2 & 0 & 210 & 1.633 & 0.644 & 0.044 \\
\hline 7 & 1 & 14 & 64 & 102 & 28 & 209 & 3.679 & 0.807 & 0.056 \\
\hline 8 & 20 & 143 & 35 & 11 & 0 & 209 & 2.177 & 0.667 & 0.046 \\
\hline 9 & 53 & 109 & 31 & 10 & 5 & 208 & 2.062 & 0.901 & 0.062 \\
\hline 10 & 35 & 105 & 43 & 27 & 0 & 210 & 2.295 & 0.896 & 0.062 \\
\hline 11 & 47 & 108 & 28 & 22 & 3 & 208 & 2.163 & 0.944 & 0.065 \\
\hline 12 & 1 & 15 & 47 & 127 & 19 & 209 & 3.708 & 0.751 & 0.052 \\
\hline 13 & 26 & 90 & 29 & 58 & 7 & 210 & 2.667 & 1.108 & 0.076 \\
\hline 14 & 7 & 35 & 46 & 86 & 36 & 210 & 3.519 & 1.064 & 0.073 \\
\hline 15 & 44 & 147 & 14 & 4 & 1 & 210 & 1.91 & 0.624 & 0.043 \\
\hline 16 & 33 & 121 & 32 & 20 & 2 & 208 & 2.216 & 0.86 & 0.06 \\
\hline 17 & 104 & 87 & 10 & 5 & 0 & 206 & 1.592 & 0.698 & 0.049 \\
\hline 18 & 41 & 33 & 29 & 67 & 39 & 209 & 3.144 & 1.414 & 0.098 \\
\hline 19 & 44 & 134 & 18 & 12 & 1 & 209 & 2.005 & 0.756 & 0.052 \\
\hline 20 & 5 & 62 & 45 & 75 & 23 & 210 & 3.233 & 1.066 & 0.074 \\
\hline 21 & 34 & 103 & 35 & 31 & 6 & 209 & 2.388 & 1.018 & 0.07 \\
\hline 22 & 9 & 50 & 47 & 63 & 41 & 210 & 3.367 & 1.167 & 0.081 \\
\hline 23 & 10 & 60 & 37 & 80 & 21 & 208 & 3.202 & 1.111 & 0.077 \\
\hline 24 & 7 & 76 & 49 & 65 & 10 & 207 & 2.976 & 1.007 & 0.07 \\
\hline 25 & 5 & 54 & 43 & 74 & 34 & 210 & 3.371 & 1.105 & 0.076 \\
\hline 26 & 35 & 60 & 62 & 47 & 5 & 209 & 2.651 & 1.078 & 0.075 \\
\hline 27 & 7 & 47 & 47 & 82 & 25 & 208 & 3.341 & 1.06 & 0.074 \\
\hline 28 & 7 & 29 & 43 & 110 & 20 & 209 & 3.512 & 0.961 & 0.066 \\
\hline 29 & 19 & 90 & 51 & 45 & 4 & 209 & 2.641 & 0.981 & 0.068 \\
\hline 30 & 13 & 83 & 53 & 50 & 10 & 209 & 2.813 & 1.023 & 0.071 \\
\hline 31 & 65 & 111 & 16 & 14 & 2 & 207 & 1.928 & 0.864 & 0.06 \\
\hline 32 & 78 & 110 & 16 & 6 & 0 & 210 & 1.762 & 0.712 & 0.049 \\
\hline 33 & 18 & 97 & 27 & 53 & 14 & 209 & 2.751 & 1.129 & 0.078 \\
\hline 34 & 82 & 111 & 10 & 4 & 0 & 207 & 1.691 & 0.654 & 0.045 \\
\hline 35 & 2 & 54 & 88 & 61 & 4 & 209 & 3.053 & 0.816 & 0.056 \\
\hline
\end{tabular}




\section{On The Whole}

Overall, the data reveals a slight gap between theory and practice. There was a certain unanimity to the tutors' answers, indicating that perhaps we are indeed bound tightly by our ideas. All of them had internalized a similar philosophy towards tutoring, but none were grounded completely by this philosophy, acknowledging the need to adapt to a session's context. Tutor 13 verbalizes this quite well (italics are mine):

It's pretty safe to say that tutors shouldn't be too directive, should let the tutee do the work, should facilitate rather than direct...all ancient writing centre clichés, and probably true, but the list of dos and don'ts is infinite and dependent on the moment.

The tutors had few qualms about stepping out of the comfort zone provided by the student-centered paradigm; they did, however, feel the need to justify their actions, further demonstrating the hold our ideology has on tutors. Nonetheless, they broke with basic writing centre philosophy on a regular basis, and practically none of them felt that this was a serious problem.

This does not necessarily indicate a discomfort or discontent with writing centre philosophy; rather, the tutors simply found writing centre ideals to be quite malleable and open-ended, and thus applied them selectively. More than that, they felt obliged to be selective; it was their duty, their responsibility. As Tutor 14 wrote, "I can't imagine there being a mandate of any sort that would require a method that would go against a tutor's better judgment." Writing advice was dispensed with care, shaped by the context of a session and the wherewithal of the individual tutor. The work of a tutor is wholly 
contextual, as Tutor 14 says, "dependent on the moment." To borrow from Schön once more, "our knowing is ordinarily tacit, implicit in our patterns of action and in our feel for the stuff with which we are dealing. It seems right to say that our knowing is in our action" (49). Ultimately, the data shows that our "action," even as it is informed by a somewhat uniform theoretical base, is complex, fluid and varied, full of contradictions and subject to a multitude of different interpretations and practical applications. As such, the writing centre is - today, tomorrow, and always - a "text still in the process of composition" (Hemmeter, 1990). 


\section{CHAPTER FIVE}

\section{CONCLUSION}

\section{Chapter Overview}

This chapter separates noteworthy implications of my findings into four sections with respect to my research questions (see Chapter 1). The first section functions as both a general introduction to the chapter and a broad conclusion to the study. The second section deals with implications vis-à-vis shared writing centre ideals, specifically tutor talk and social keenness. The third section explores conclusions drawn from various double bind situations, including directive/non-directive tutoring, process and product, higher and lower order concerns with NNS writers, and the writing to learn/learning to write. The fourth section explores the notion of the writing centre as a "service," calling into question some of our most basic assumptions. I end the chapter with some closing words about the study as a whole.

\section{Introduction}

For all the proactive dialogue about writing centres - working definitions of our mission, attempts to carve out our own niche -- we are unequivocally reactive entities, subject to the needs/demands of our institutions and the context of particular tutorial sessions. Kinkead and Harris say, "writing centres are frequently described in terms of an ideal or an abstraction - a vision of what should be rather than what is" (xv). This study shows writing centres to be quite similar in terms of philosophical bases and expressed pedagogical styles. However, the vast majority of participants regularly advocated and utilized approaches to tutoring that directly contradicted these 
foundational notions. It can be said, then, that the reality of writing centre practice often contradicts our theoretical "vision."

Tutorial sessions often call for methods that are completely antithetical to writing centre theory. Tutors, when faced with these contradictions, learned to apply different teaching strategies carefully and selectively, adapting to the situation at hand. Double binds, then, serve a constructive purpose: to disrupt our comfortable, holistic writing centre orthodoxy and force tutors to adopt a set of new activities, a "contradictory unit of the given new and the created new" (Engeström Learning 16). Decisions are made in light of these contradictions. Tutors become more flexible and adaptable, allowing them to alleviate or completely eliminate the double bind. Let us revisit some of our shared ideals and recurrent double binds that appeared throughout this study.

\section{Shared Ideals}

\section{Tutor Talk}

This study provides important insights into North's notion of "talk" as the primary guiding element in a session. What is important in this study is not that a tutor talks, but the nature of that talk and what is specifically talked about. North proclaims, "If the writing centre is to prove its worth in other than quantitative terms [...] it will have to do so by describing this talk; what characterizes it, what effects it has, how it can be enhanced" (444). These results reveal the extent to which our "talk" is socially infused, often less about tutoring than building a working relationship. Let us again consider Tutor 18's description of our talk:

I may slow down or speed up my speech, keep pretty monotone and reserved or laugh along with a client, etc. I speak in pace with them - the actual language (using terminology that seems within their realm) and 
physically matching the rhythm of their speech. I have found this soothes nervousness and brings client and tutor to the same level.

Tutors in this study were acutely aware of the dynamics in a tutorial session, and understood the need to act not only as a critical "auditor" (North 440), but also as a facilitative guide, supportive peer, and empathetic friend. Their responses reflected their social keenness, a sort of interpersonal intelligence that allowed them to interact successfully with their students. It is perhaps not just "talk," but the subtle, discursive, sometimes less-than-academic nature of that talk, that defines the tutorial session.

"Social Keenness"

As the results showed, both tutors and directors placed a great deal of emphasis on making the writing centre an inviting, comfortable place, someplace like "home." Jackie Grustch McKinney seeks to explain and critique this notion. She worries that writing centres are overemphasizing the "affective" dimension of tutoring and marginalizing the "intellectual" (18). She sees writing centres as having been "gendered" female, since the positions in them are disproportionately held by women. As such, when a writing centre is made to "feel like home," it may be an attempt to provide a "female space in opposition to the institution at large, which [is] male, uncomfortable, foreign" (17). She goes so far as to say, "Female directors who insist on cozy, inviting spaces may be unwittingly narrating their work as nonintellectual" (17). A "homey centre," McKinney says, encourages students to "lounge, sit back, [and] relax" (18) instead of becoming active learners. McKinney further asserts that writing instruction does not always have to be "comfortable," and advocates a more confrontational and unsettling approach: 
If writing centers are imagined as homes, they are consciously constructed as private spaces where writers can retreat. [However,] Conflict is not to be avoided but engaged to prepare students for life outside their classrooms. Working through conflict can teach students how to use a public voice. Students will not get practice using a public voice or engaging in public discourse if the tutoring is carefully crafted to nurture.

McKinney, seemingly, would prefer a space that does less nurturing and actually encourages conflict, using it as a catalyst for new ideas. Her notions of gender seem less relevant to this study, as both male and female tutors promoted a "homey" writing centre. However, as so many tutors presumed that a writing centre must be - as if by definition inviting and comforting, her ideas must give us pause. In our attempts to make the writing centre a safe haven (a worthy pursuit, to be sure), we must be careful not to exchange one problem for another, replacing confusion and displacement with no more than fatuous feelgoodism.

To fully assess the relationship between practice and theory, even our most basic paradigmatic assumptions must be questioned. Certainly, McKinney is not the first to point out that writing students may need to be uncomfortable in order to learn (Clark, "Maintaining Chaos"; Boquet, "Noise"). If this study is any indication, notions of a "homey" writing centre are widespread, if not ubiquitous. The idea warrants further research with more intensive examination and scrutiny. 


\section{Double Binds}

\section{Directive/Non-Directive Tutoring}

Clearly, tutors are acting in a directive manner, and with few qualms or reservations about it. Rather than dwell on the antiquated question, "should tutors be directive," researchers might instead focus on to what extent and under what circumstances tutors are directive. It is no longer a matter of a tutor being directive or not, but rather where that tutor falls on what Irene Clark calls the "directive/non-directive continuum" (33). In many cases, strategies commonly perceived as mutually exclusive (i.e., you are either collaborative or directive) can work in conjunction with one another. This is not an either/or issue, and certainly not as dichotomous as it once was. Ultimately, the context of the session should be the primary determiner of directiveness.

\section{Conflicted role of "peer"}

Authority, control, and power are all but inevitable in a conversation.

Consequently, some student-tutor relationships simply are not and cannot be peer-based. Not all tutors can realistically see their students as peers. Moreover, students do not always see their tutors as peers. Many students come to the writing centre for no other reason than to talk to someone who knows more about writing than they do. As with the directive issue, there is a middle ground that tutors can assume; responding to the context of the session is key. 


\section{Process and Product}

Like directive and non-directive approaches, process and product are more polarized in theory than in practice. Some tutors endeavored to reconcile the two goals of process and product:

The student should leave the writing centre with a better paper and as a better writer. (Tutor 5)

As I tutor, I try to improve the student's understanding of writing as an act, as a process, and as a product. (Tutor 7)

These declarations of intent are reminiscent of the aforementioned mission statements on writing centre websites, many of which include the maxim, "making better writers, not just better papers." In this case, the "just" is extremely important, as it encourages tutors and tutees to find common ground between process and product. The writing-as-process movement had/has a tendency to portray process/product as mutually exclusive, as North did in his original characterization of writing centre work as "producing better writers, not better writing" (438). With this statement, North advocates process in lieu of product, as if product somehow ceases to be important in light of more holistic concerns. His statement almost seems to say, "We care about you as a writer, but not the paper you brought us." In practice, of course, this is hardly the case, and almost certainly not the message North meant to convey. Tutors, as these results show, are not nearly so dogmatic.

Still, when asked to theorize about what they do, some tutors still categorically reject product-based instruction. Take Tutor 18's comments as an example (italics are mine): "I want to tutor a writer, not a piece of writing. My goal isn't to help them with 
one assignment, but to give clients skills to apply to all the writing they do". This statement, like North's, trivializes the paper (the product) itself as something she does not want to work on. Granted, this is a decontextualized statement; in reality, tutors - Tutor 18 probably amongst them - attend to a variety of process and product-based needs. Nonetheless, some tutors, when defining themselves, will retreat into a process-only mentality. This is unfortunate, not only because it is an inaccurate portrayal of what they actually do, but also because statements like these can alienate students who simply have not yet thought outside the context of a single paper. Product and process are not necessarily in diametric opposition to one another. Based on the approaches and methods advocated in this study, the writing centre community - at least in practice - seems to be fully aware of this. It follows, then, that they should resist the lingering urge to denigrate all product-based instruction when speaking theoretically.

\section{Order of Concerns - NNS writers}

The tutors in this study very often elevated mechanics to the level of higher-order concerns when an NNS student was involved. Eli Hinkel, speaking not from a writing centre perspective, but as an ESL teacher and researcher, encourages writing instructors to focus on form. He claims that process writing pedagogy, so often embraced as an axiomatic truism, is fundamentally inappropriate for NNS writers:

The new instructional methodology centered squarely and almost exclusively on the writing process that fundamentally overlooked the fact that NNS writers may simply lack the necessary language skills (e.g. vocabulary and grammar) to take advantage of the benefits of writing process and instruction. (9) 
Gillespie and Lerner, however, treat this very idea - "NNS writers just need more of the basics before they can move on to more substantial tasks" - as a "persistent and dangerous myth" (121). My study - particularly the survey - seemed to reflect both of these disparate notions, indicating that this is an issue with which we have not come to terms, one that requires further scrutiny, further theorizing, and further research.

\section{Writing to Learn}

Michael Foucault once said, "I write in order to change myself, in order to not think the same things as before" (239-240). Tutors, as self-proclaimed student-centered holists, approach sessions as if informed by this statement. But is this really why students write? Tutees are writing within specific constraints for a particular audience. Students are more often writing to fulfill a requirement, to receive a grade, to complete the process; rarely are they "writing to learn."

There was one tutor who expressed discontent with North's dictum:

I think the blanket goal of 'producing better writers' is sufficiently vague to make it meaningless. What does that mean? Writers of what? Writers for whom? Writers in what context? There is no single definition of 'good writing' and so there can't be one goal of producing better writers, no single way to achieve this production. (Tutor 10)

This tutor is uncomfortable with focusing on "writers" as individuals, since their writing cannot be evaluated outside of its context. While it seems doubtful that North meant to ignore context in his decree, the tutor may have identified a potential issue. Expressivist notions of writing have been criticized for failing to attend to social and political constraints (Writing with Elbow). Tutors, almost all of whom saw their job as "producing 
bettur writers," run of the risk of valuing the individual writer over the larger sociopolitical context of the writing. Tutees are more likely to produce "transactional" (Britton 107) writing - functional writing with a distinct purpose - than "expressive" writing. When tutors focus on the "self" and "writing to learn," they may miss the fact the many students are merely using writing as a practical tool, and are completely removed from the writing they produce.

\section{Defining ourselves: Are we really a service?}

All these double binds can be traced to a fundamental disparity not between student and tutor, but between students and our ideology. When tutors are expected to be directive, to make lower-order concerns a priority, they are left with a very uncomfortable choice, torn between complying with the student but going against writing centre ideals, or adhering to writing centre philosophy and alienating the desires of the student, who is supposed to be at the very centre of our practice. How can we be student-centered if we do not do what the student wants?

Tutor 19 wrote: "One must remember, though, that this is still the service business. We must cater to a student's needs." Not all of the tutors framed their practice in this way, but enough did to give me pause. Director 4 also characterized her writing centre as a "service." Upon perusing several writing centre web sites, I found that many characterize themselves as a "service." Service? To what extent can the writing centre be termed a "service"? If it is a service, we may have to re-think who it is that we are serving. Are we really student-centered? Could we be self-centered?

Consider this reflection by Tutor 7: "The writing they've brought in with them is writing they've already done, and I'm more interested in the writing they will do in the 
future." Tutor 7 is merely redirecting the student towards process-based concerns, but to a distraught student with deadlines to meet, he may as well have said, "I'm not really interested in working with this particular paper." The tutor - not the student - set the goals for this session. Improving a student's writing, not just one paper: that is our goal for them. We may even have to qualify our student-centeredness, because while our intention is to empower the student, we are not always doing what the writer actually wants.

Tutor 20 describes the bitterness that can result from service-based expectations: I had a tutee the other week who wanted me to look over her personal narrative for grammar mistakes, but I found that she needed help with more than just grammar. She was very wordy in a lot of instances and didn't really have a strong focus for her paper. When I explained these things to her, she reacted rather negatively and seemed angry. By the end of the session, I could tell that she was upset because I gave her more things to think about...given that she only wanted grammar help.

Tutor 20 goes on to say, "I don't think the tutor should ignore problem areas just because the writer didn't specifically say to work on it." Tutor 20 claims to have the needs of the student in mind. However, in this case, it is the tutor's conception of the writing that determines this need. If the student wants grammar help, and we re-direct him/her to HOCs, can we really call that "student-centered" instruction? When students want one thing and receive another, it may be a stretch to call that a "service."

Tutors sometimes enter a session with a very specific "ideal" in mind, which may run contrary to what tutees want: 
In the best-case scenario, discussion of the relationship between the writing and the assignment represents a dialectic that the student might internalize in the future [...] This isn't always what the student needs, or feels that he or she needs, though. (Tutor 7)

This is a very telling statement. Tutor 7 admits to conceiving of an ideal tutor-student dynamic, a "best-case scenario." However, as he is aware, any preemptively defined "best-case scenario" has been constructed without regard to student need. A tutor, in his/her anticipatory efforts to live up to the "ideal" session, runs the risk of ignoring student requests. Indeed, the conception of an "ideal" session may lead to self-fulfilling prophecy.

Here is yet another example:

Least important in my tutoring session is grades and/or pleasing the teacher $[\ldots]$ Writing in college is to benefit the student. Of course, I want students to get good grades, but I'd much rather them be excited about writing or proud of a final product than agonize over getting every bullet point of a teacher's writing prompt taken care of. (Tutor 17)

In this situation, is Tutor 17 really serving the student's best interest? Agonizing over a teacher's writing prompt is part of writing in an academic context. Tutor 17 may not care about grades, but her tutees most assuredly do. As Tutor 10 says, "writing is always done with a purpose for some reader. As a writing tutor, by definition, that reader is not you, so in some ways it's an odd position to be in." In this case, Tutor 17 is basing the session on her own conception of the student's needs, rather than on the actual context of the writing. Sometimes, as in this case, our student-centeredness is almost parental, 
imbued with an implicit "we know what's best for you" mentality. Ironically, we are, to some degree, serving our own interests, pursuing our own conception of what students should get from the sessions, rather than what they want. Admittedly, some students really do not know what they want, and often enough tutors do know better, but when we guide them away from their own initial desires, are we practicing a service?

There is a difference here - a difference between what a student wants and what a student needs. We are catering to the latter, as we probably should. However, it follows that those of us who insist the session is unequivocally in the hands of the student are being somewhat insincere. Students, as the data shows, often have different goals, and we don't always plan on working towards those goals. Often, student priorities are little more than an afterthought to a tutor, who eschews this immediacy and tries to "redirect" (a word that recurs in the data) the session towards long-term, process based concerns.

Tutor 7 laments a session in which he was unable to "shift" the discussion away from mechanics. His student was "uninterested in talking about writing in any abstract way $[. .$.$] became irritated [and] repeatedly insisted that the writing centre was here to$ 'make it right', and pointed to the paper over and over again." Obviously, in this case, there is a misunderstanding about the nature of writing centre instruction; nonetheless, it may be unrealistic to expect some students to embrace the idea of discussing writing in an "abstract way." They often approach the writing centre as a "service" for very specific help, and when we fail to provide it, some grow understandably frustrated.

I'm not saying that ours is a bad approach - to do so would undermine the very heart of our practice - but we should call it what it is. Some tutors in this study thought that students should determine the priorities and focus in a session, but they were in the 
minority. All tutors said they would adapt their session based on student need, but by and large it was the tutors - not the students - who determined the nature of that need. First-time students in the writing centre are essentially newcomers in an entirely different academic world, one in which we, the writing centre community, have determined the parameters, the goals, and educational philosophy. Suddenly, the priorities these students hold dear - external text characteristics, grades - cease to be the focal point of their learning. Throughout all this, we tell them we are student-centered. Is any surprise that some of these students are confused and resentful?

Instead of being defensive and retreating into our ideology when faced with double binds, we have to acknowledge that we exist in a very unique learning environment, essential and meaningful to us, but thoroughly baffling to those who are unfamiliar with it. Frustrating as it may be (and no doubt is), it is our job to bridge the gap, explain ourselves, and make students comfortable so that they can continue to learn. This is the function of the abovementioned social keenness, and why it is of such importance in a tutorial session.

Pedagogy that adheres too rigidly to ideology runs the risk of becoming selfserving and dominant. Bokser speaks to this notion: "Writing is more accurately understood as both aggression and charity. With only a slight shift in perspective, what appears to be help ('charity') might be understood as the violence of imposition and self aggrandizement" ("Peer Tutoring" 23). Bawarshi takes this a step further; he fears that we may be "imposing academic discourse on marginalized writers and calling it a 'service"” (51). While I don't see us as involved in quite so hegemonic a relationship, he may have a point. The "service" model advocated by Tutor 19 is by no means 
ubiquitous, but it does seem to exist. It is sncumbent on those writing centres that characterize themselves as services to consider these issues, to reflect upon and reconsider the nature of their instruction and the philosophy that informs it. Further research might look specifically at the self-serving implications of our ideology.

\section{Closing Comments}

I do not mean to undermine our theories and basic philosophy; in fact, I endorse them wholeheartedly. I merely intend to offer some perspective. In the words of Hillocks, Jr., "We have a tendency to think of theories as being 'discarded' and new ones 'replacing' them. A more useful metaphor may be to think of theories as evolving" (51). I am not advocating a complete overhaul of writing centre theory, only suggesting that some critical assumptions be questioned, and that the theory evolve appropriately to fit its practical application. The extent to which tutors may occasionally be directive, formfocused, etc., simply is not always reflected in the scholarship about writing centres. Therein lies the disparity, however slight. Discussions are often overly polarized - i.e., student-centered: good, tutor-centered: bad - but the truth is rarely so cut and dry.

This largely reflective study does not reinvent the wheel, but it does, in a sense, reintroduce the wheel, saying something explicitly that was previously implicit. I suspect most tutors already have a tacit awareness of the disparities between theory and practice. If my results are any indication, tutors are being directive, are standing the order of concerns on their head, and are violating basic premises for tutoring. Perhaps this is a good thing. As Elizabeth Boquet says, "the writing centre is most interesting to me for its post-disciplinary possibilities, for the contradictions it embraces, for its 
tendency to go off-task" ("Our Little Secret" 478). It appears to be this adaptability more than our shared theories - that defines who we are.

The data in this study encourages us to move towards a "higher-risk/higher-yield" model of writing centre work, such as that advocated by Boquet, who encourages a tutor to challenge and extend the parameters of a session, to "operate at the edge of his/her expertise" (Noise 81). Through this lens, our philosophy can be seen as fluid and dynamic, not as something to which we choose to adhere (or not), but instead as something that is continually constructed and reconstructed.

Perhaps, in the writing centre, our world is, to quote Artemeva and Freedman, best "conceptualized as a verb rather than a noun" (178). Self-definition, usually in the form of nouns, has led to a great deal of disagreement in writing centre circles. Nouns appear as fixed, stable ideas; people often preemptively associate them with a particular context. Verbs, however, imply action, movement, and change. Our focus should be on what we $d o$, rather than on what we are (or are not). We facilitate, we question, but we are not unequivocal facilitators or questioners. We may, in certain circumstances, direct a student, but we are not authoritarians. In light of all the evidence provided in this study, the one constant is that there are no constants. We are peers and teachers, directive and non-directive; we are making better writers and better papers. The writing centre is an organic, fluid space and we - as tutors, directors, students, and theorists - must adapt to its dynamic context.

As mentioned before, we define ourselves not only in terms of what we are, but also what we are not. It is, for all practical purposes, a defense mechanism. Many published articles on writing centres offer a rhetorical or institutional "defense" of the 
writing centre. The very idta of a "defense" implies that we feel marginalized and/or threatened. Because of our limited space, resources, and elusive collective identity, writing centre personnel typically operate in a defensive mode, constantly backpedaling, qualifying and explaining exactly what it is we do. In doing so, we may sometimes construe ourselves more narrowly on paper than our practice would otherwise dictate.

Our philosophy, after all, provides only a purely theoretical argument. Writing centre philosophy, even when it is well intentioned, can be inflexible or orthodox. The idealized student-centered session exists in a vacuum, away from the day-to-day double binds experienced by tutors on the job, where directive tutoring and focus on form are not just acceptable, but often necessary. Perhaps, as Sunstein says, writing centres exist "between the lines," (9) defined as much by an "absence of culture" (13) as they are by that which occurs in them.

In summary, the perception of who we are varies drastically from student to student, instructor to instructor, and institution to institution. In our continuous, often laborious efforts to carve out our own niche, to define ourselves, distinctively and wholly, we cannot ignore the contextual nature of writing. It is extraordinarily difficult to distill writing centre philosophy into a set of universally acceptable, all-encompassing ideals. While our common ground is undeniably important, we must acknowledge the fact that each centre is its own individual entity, "filled with mixed cultural patterns and human insights" (Sunstein 11). As Barnett says, "Because we all exist in highly specialized environments, I believe we need also to define ourselves vis-à-vis these environments" (123). It is all but impossible to extract the writing centre from its social and institutional context. The contextual nature of writing centre work ultimately 
necessitates not only that theory inform our practice, but also that practice inform our theory. 


\section{WORKS CITED}

Adair, G. "The Hawthorne Effect: A Reconsideration of the Methodological Artifact" Journal of Appl. Psychology 69 (2): 334-345, 1984.

Artemeva, Natasha and Aviva Freedman. "'Just the Boys Playing on Computers': An Activity Theory Analysis of Differences In the Cultures of Two Engineering Firms." Journal of Business and Teachincal Communication 15.2 (2001): 164-94. Bakhtin, Mikhail. “The Problem of Speech Genres." Speech Genres and Other Late Essays. Eds. Caryl Emerson and M. Holquist. Austin, TX: University of Texas Press, 1986.

Barnett, Robert W. "Redefining our Existence: An Argument for Short- and Long-term Goals and Objectives." Writing Center Journal 17.2 (1997): 123-131.

Bawarshi, Anis and Stephanie Pelkowski. "Postcolonialism and the Idea of a Writing Center." Writing Center Journal 19.2 (1999): 41-58.

Bell, Jim. “Tutor Training and Reflection on Practice.” Writing Center Journal. $21.2(2001): 79-98$.

Bishop, Wendy. Ethnographic Writing Research: Writing it Down, Writing it Up, and Reading It. Portsmouth, NH: Heinemann, 1999.

Blau, Susan R., John Hall, and Tracy Strauss. "Exploring the Tutor/Client Conversation: A Linguistic Analysis." Writing Center Journal 19.1 (1998): 19-48.

Blau, Susan, John Hall and Sarah Sparks. "Guilt-Free Tutoring: Rethinking How We Tutor Non-native-English-Speaking Students." Writing Center Journal 23.1 (2002): 23-44.

Bokser, Julie A. "Am I Really a Peer? Dilemmas of Collaboration for the Tutor with 
Work Experience." Writing Lab Newsletter 24.9 (2000): 5-8.

Bokser, Julie A. "Peer Tutoring and Gorgias: Acknowledging Aggression in the Writing Center." Writing Center Journal 21.2 (2001): 21-34.

Boquet, Elizabeth. Noise from the Writing Center. Logan, UT: Utah State University Press, 2002.

Boquet, Elizabeth. "Our Little Secret: A History of Writing Centers, Pre- to PostOpen Admissions." College Composition and Communication 50.3 (1999): 463482.

Brookfield, Stephen D. "What It Means to be a Critically Reflective Teacher." Becoming a Critically Reflective Teacher. San Francisco: Jossey-Bass, 1995. 1-27.

Brooks, Jeff. "Minimalist Tutoring: Making the Student Do All the Work." Writing Lab Newsletter 15.6 (1991): 1-4.

Brufeee, Kenneth. "Training and Using Peer Tutors." College English 40 (1978): 43249.

Carino, Peter. "What Do We Talk About When We Talk About Our Metaphors: A Cultural Critique of Clinic, Lab, and Center." Writing Center Journal 13.1 (1992): 31-42.

Cheng, L., Fox, J., and Zheng, Y. “Towards a Better Understanding of Academic Acculturation: Second Language Students in Canadian Universities. Currently unpublished/under review.

Clark, Irene Lurkis. "Collaboration and Ethics in Writing Center Pedagogy." Writing Center Journal 9.1 (1988): 3-12.

Clark, Irene. "Perspectives on the Directive/Non-Directive Continuum in the Writing 
Center." Writing Center Journal 22.1 (2001): 33-58.

Cogie, Jane, Kim Strain, and Sharon Lorinskas. "Avoiding the Proofreading Trap: The Value of the Error Correction Process." Writing Center Journal 19.2 (1999): 7 32.

Copeland, Willis D. and Carrie Birmingham. "The Reflective Practitioner in Teaching: Toward a Research Agenda." Teaching and Teacher Education 9.4 (1993): 347 359.

Denzin, Norman K. The Research Act: A Theoretical Introduction to Sociological Methods (2 $2^{\text {nd }}$ edition). New York: McGraw Hill, 1978.

"Description of Class Visits." Penn State Undergraduate Writing Center. 1 December $2005<$ http://www.psu.edu/dept/cew/writingcenter/UWC/description.htm $>$

Dewey, John. How We Think. Lexington, MA: D.C. Heath, 1910.

Dinitz, Sue and Jean Kiedaisch. "Creating Theory: Moving Tutors to the Center." Writing Center Journal 23.2, (2003): 63-76.

Ede, Lisa. "Writing as a Social Process: A Theoretical Foundation for Writing Centers?" Writing Center Journal 9.2 (1989): 3-13.

"The Effective Writing Program: Frequently Asked Questions." University of Western Ontario Student Development Services. 16 April 2007 $<$ http://www.sdc.uwo.ca/writing/index.html?faq\#q8 >

Elbow, Peter. Embracing Contraries: Explorations in Learning and Teaching. New York: Oxford University Press, 1986.

Elbow, Peter. Writing With Elbow. Logan, UT: Utah State University Press: 2002. Engeström, Yrjo and Reijo Miettinen. "Introduction." By Engeström and Miettinen. 
Perspectives on Activity Theory. Cambridge, UK: Cambriỏge University Press, 1999.

Engeström, Yrjo. Learning by Expanding. Helsinki: Orienta-Konsulti, 1987. <http://lchc.ucsd.edu/MCA/Paper/Engestrom/expanding/toc.htm>

Erikson, Erik. "The Nature of Clinical Evidence.” Evidence and Inference, Ed. Daniel Lerner. Glencoe, IL: The Free Press of Glencoe, 1958.

"Five Major Rules for Lab Tutorials." Purdue University Online Writing Lab. 16 March $2007<$ http://owl.english.purdue.edu/writinglab/topic/majorrules $>$

Foucault, Michel. The Essential Works 3: Power. London, Allen Lane: The Penguin Press, 2001.

"Frequently Asked Questions." Carleton University Academic Writing Center and Writing Tutorial Service, 2007. 19 September 2006 <http://www.carleton.ca/wts/faq.html\#howwtshelps>

Gardner, Philip J. and William M. Ramsey. "The Polyvalent Mission of Writing Centers." Writing Center Journal 25.1 (2005): 25-42.

Gillespie, Paula, Alice Gilliam, Lady Falls Brown, and Byron Stay (Eds.). Writing Center Research: Extending the Conversation. Mahwah, NJ: Lawrence Erlbaum Associates, 2002.

Gillespie, Paula, and Neal Lerner. The Allyn and Bacon Guide to Peer Tutoring. New York: Pearson-Longman, 2004.

Gilliam, Alice. "Collaborative Learning Theory and Peer Tutoring Practice." Intersections: Theory-Practice in the Writing Center. Ed. Joan A. Mullin and Ray Wallace. Urbana, IL: NCTE, 1994. 39-53. 
Harris, Muriel. "Collaboration Is Not Collaboration Is Not Collaboration: Writing Center Tutorials vs. Peer Response Groups." College Composition and Communication 43.3 (1992): 369-83.

Harris, Muriel. Teaching One-to-One: The Writing Conference. Urbana: NCTE, 1986. Healy, David. Tutorial Role Conflict in the Writing Center. Writing Center Journal $11.2(1991): 41-50$.

Hemmeter, Thomas. "The 'Smack of Difference': The Language of Writing Center Discourse." Writing Center Journal 11.1 (1990): 35-48.

Henning, Teresa B. "Theoretical Models of Tutor Talk: How Practical Are They?" Paper presented at the Annual Meeting of the Conference on College Composition and Communication. Denver, CO. March 15, 2001. "Higher Order Concerns (HOCs) and Lower Order Concerns (LOCs)." 1995-2004. Purdue University Online Writing Lab. 1 December 2005 $<$ http://owl.english.purdue.edu/handouts/general/gl hocloc.html $>$ Hillocks, Jr., George. Teaching Writing as Reflective Practice. New York: Teacher's College Press, 1995.

Hinkel, Eli. Teaching Academic ESL Writing: Practical Techniques in Vocabulary and Grammar. Mahwah, NJ: Lawrence Erlbaum Associates, 2004.

Hobson, Eric H. "Maintaining Our Balance: Walking the Tightrope of Competing Epistemologies.” Writing Center Journal 11.1 (1990): 35-48.

Imel, Susan. "Reflective Practice in Adult Education." 1992. Eric Digest No. 122. 11 November $2005<$ http://www.ericdigests.org/1992-3/adult.htm>

Kaplan, Robert B. "Contrastive Rhetoric and Second Language Learning: Notes Towards 
a Theory of Contrastive Rhetoric." Writing Across Language and Cultures: Issues in Contrastive Rhetoric. Ed. Alan C. Purves. Newbury Park, CA: Sage, 1988. 275-04.

Kim, Katherine Yungmee. "Better Writers, Not Just Better Papers: Students Embrace College Writing Program." University of California College of Letter, Arts, and Sciences. August 2004. 22 February 2007 <http://www.usc.edu/schools/college/news/august 2004/writing program.html> Kinkaid, Joyce A. and Jeanette G. Harris, Eds. Writing Centers in Context. Urbana, IL: National Council of Teachers of English, 1993.

Leontev, A.N. Activity, Consciousness, and Personality. Hillsdale: Prentice-Hall, 1978. Lundell, Dana Brit and Richard Beach. "Dissertation Writers Negotiations with Competing Activity Systems. Writing Selves/Writing Societies: Research from Activity Perspectives. Eds. Charles Bazerman and David Russell. Fort Collins, CO: The WAC Clearinghouse and Mind, Culture, and Activity, 2003. 483-514. McAlpine, Lynn and Cynthia Weston, Denis Berthiaume, Gail Fairbank-Roch, and Michele Owen. "Reflection on Teaching: Types and Goals of Reflection." Educational Research and Evaluation 10.4-6 (2004): 337-363.

McCall, William. "Writing Centers and the Idea of Consultancy." Writing Center Journal 14.2 (1994): 163-171.

McKinney, Jackie Grustch. "Leaving Home Sweet Home: Towards Critical Readings of Writing Center Spaces." Writing Center Journal 25.2 (2005): 6-20.

Meyer, Emily and Louise Z. Smith. The Practical Tutor. New York: Oxford UP, 1987. Myers, Sharon A. "Reassessing the Proofreading Trap: ESL Tutoring and Writing 
Instruction." Writing Center Journal 24.1 (2003): 51-70.

North, Stephen A. “The Idea of a Writing Center." College English 46.5 (1984): 433446.

North, Stephen A. "Revisiting the idea of a Writing Center." Writing Center Journal $15.1(1994): 7-19$

Petit, Angela. “The Writing Center as 'Purified Space': Competing Discourses and the Dangers of Definition.” Writing Center Journal 17.2 (1997): 111-123.

Powers, Judith. "Rethinking Writing Center Conferencing Strategies for the ESL Writer." Writing Center Journal 13.2 (1993): 39-47.

Riley, Terrance. "The Uncompromising Future of Writing Centers." Writing Center Journal 15.1 (1994): 20-33.

Runciman, Lex. "Defining Ourselves: Do We Really Want to Use the Word Tutor?" Writing Center Journal 11.1 (1990): 27-34.

Russell, David. "Rethinking Genre in School and Society: An Activity Theory Analysis." Written Communication 14 (1997): 504-54.

Santa, Tracy. “Writing Center Orthodoxies as Damocles' Sword: An International Perspective." Writing Center Journal 22.2 (2002): 29-38.

Schön, Donald. The Reflective Practitioner. New York: Basic Books, 1983.

Schön, Donald. Educating the Reflective Practitioner. San Francisco: Jossey-Bass, 1988.

Shamoon, Linda K. and Deborah H. Burns. "A Critique of Pure Tutoring." Writing Center Journal 15.2 (1995): 134-151.

Shaughnessy, Mina P. Errors and Expectations: A Guide for the Teacher of Basic 
Writing. New York: Oxford UP, 1977.

Smart,Graham. Writing the Economy: Activity, Genre, and Technology in the World of

Banking. Oakville, CT: Equinox Publishing, Ltd., 2006.

Sollisch, James. "From Fellow Writer to Reading Coach: The Peer Tutor's Role in Collaboration." Writing Center Journal 5.2 (1985): 10-14.

Sunstein, Bonnie S. "Moveable Feasts, Liminal Spaces: Writing Centers and the State of In-Betweenness." Writing Center Journal 18.2 (1998): 7-26.

“The Writing Center at Randolph Macon.” 2005. College Offices. 1 December 2005 $<\underline{\text { http://www.rmc.edu/directory/offices/hac/wac/mission.asp }>}$

Thonus, Therese. "Triangulation in the Writing Center: Tutor, Tutee, and Instructor Perceptions of the Tutor's Role." Writing Center Journal 22.1 (2001): 59-81.

Thonus, Therese. "Tutor and Student Assessments of Academic Writing Tutorials: What is "Success"? Assessing Writing 8 (2002): 110-134.

Thonus, Therese. "Tutors as Teachers: Assisting ESL/EFL Students in the Writing Center." Writing Center Journal 13.2 (1993): 13-26.

Thonus, Therese. "What are the Differences? Tutor Interactions with First- and SecondLanguage Writers.” Journal of Second Language Writing 13 (2004): 227-42.

Trimbur, John. "Peer Tutoring: A Contradiction in Terms?" Writing Center Journal 7.2 (1987): 21-28.

Vandenburg, Peter. "Lessons of Inscription: Tutor Training and the Professional Conversation." Writing Center Journal 19.2 (1999): 59-83.

Vygotsky, Lev. Thought and Language. Cambridge, MA: MIT Press, 1986.

"What to Expect from a Tutorial Session." Carleton University Academic Writing Centre 
and Writing Tutorial Service, 2007. 19 September 2006 $<$ http://www.carleton.ca/wts/student/writing/tutoring.html\#whattoexpect $>$

Whitehead, Albert N. The Aims of Education and Other Essays. New York: Macmillan, 1929.

"Why Visit the SVSU Writing Center?" 2004. Saginaw Valley State University Writing Center. 1 December 2005.

$<$ http://www.svsu.edu/writingcenter/index.cfm?doc id=907>

Wilfrid Laurier Writing Center: Frequently Asked Questions. 16 April 2007.

$<$ http://www.wlu.ca/page.php?grp id=306\&p=3114\#What happens during $\underline{\text { an appointment }>}$

"Writing and Speaking Tutorial Services." 2005. North Carolina State Undergraduate Tutorial Center. 1 December 2005

<http://www.ncsu.edu/tutorial center/writespeak/faq.htm>

"Writing Lab Director Commentary on Sample Drafts and Responses." 2005. Eastern Oregon University Writing Lab. 1 December 2005 $<$ http://www3.eou.edu/writelab/tutordirectorcomment.htm>

“Writing Lab Information: One-on-one Tutorials." 1995-2005. The Writing Lab At Purdue. 1 December 2005 $<$ http://owl.english.purdue.edu/writinglab/topic/tutorials $>$ 


\section{APPENDIX A}

\section{Better Writers (Not Just Better Papers)}

Students embrace college writing program

By Katherine Yungmee Kim

August 2004

Norah Ashe-Mc Nalley's writing students are scientists. Some are premed, some are dental hygienists and others are majoring in such fields as sports medicine, occupational therapy and public health. Her students are pursuing careers in health care and generally speaking, when they are asked to write for their classes, they are often turning in lab reports.

Ashe-Mc Nalley teaches Writing 340 - an upper-division writing requirement for all undergraduates at USC - and she leads the Health Sciences writing workshops. Her 340 students are not only assigned to read and write about their scientific fields, they are invited to deeply consider and interpret some of its implications.

In her workshops, students read Dr. Atul Gawande's essays from Complications: A Surgeon's Notes on an Imperfect Science. They have been asked to analyze the Tuskegee study, in order to examine how such ethical transgressions in medicine could occur.

Dan Witcher, a senior majoring in biology, says that in high school he was taught to write essays that fell into a certain format. "Every paper turned out the same," he laments.

But in 340, he found the emphasis was on "finding my own voice and style, and embracing that rather than trying to fit my paper into a preconceived mold."

Ashe-Mc Nalley and her colleagues in the Writing Program are committed to making "better writers, not just better papers." They offer reading material to broaden the young writers' perspectives and interrogate the students to arrive at new ideas. Finally, they teach them proper grammar and form - tools for articulation and for learning how to be their own editors.

\section{Over 25 Years}

The Writing Program at USC College was established as an independent unit in 1978, in response to a renewed interest in rhetoric and linguistics and a widespread cultural perception that writing needed to be taught at an undergraduate level. 
For nearly two decades, the Writing Program offered Composition 101 and 102 - a mandatory, two-term freshman writing curriculum. But in 1997, as an integral part of the university's reorganization of its undergraduate general education curriculum, the Writing Program split the year-long requirement into one freshman semester and another upper-division semester: Writing 140 and 340.

This curricular structure represented, at the time and even now, an innovative approach in terms of university-level writing instruction.

Writing 140 - "Writing and Critical Reasoning" — has three principal themes: process, critique and craft. Each class is capped at 17.

Each Writing 140 section is affiliated with a general education lecture course addressing particular social issues such as "The Holocaust," "Environmental Issues in Society," and "Poverty and Welfare in America." The lecture course, with its discussion section, provides students with the concepts, theories, and topical information that form the basis for the essay assignments in Writing 140.

Dividing the classes in this manner allows Writing 140 to focus more intensely upon their writing and writing process.

Writing Program Director John Holland notes that by the time students are juniors and seniors, they have matured as both writers and critical thinkers. They take their writing more seriously and they more deeply understand the importance of writing in terms of both their academic and professional careers.

Writing 340 - "Advanced Writing" - offers instruction in writing for various audiences on topics related to a student's professional or disciplinary interests. The College offers five versions of Writing 340 - Arts and Humanities, Health Sciences, Natural Sciences, Pre-Law, and Social Sciences. There are 20 students in each class, taught by full-time faculty - all of whom have their doctorates.

Last year, student assessment of 340 ranked an outstanding 4.3 (on a five-point scale) and their evaluations of the faculty reached an unprecedented 4.7. "We're gratified to see that students have not only accepted the upper-division course," says Holland, "but they have embraced it."

More than evaluations, student accomplishment is the true litmus test for the success of the Writing Program. Genuine improvement can be charted in the quality of writing between the freshman and junior years.

It is also due to the quality of the thinker.

"Our goal," the program states, "is to make better writers. There is no better way to do this than by demonstrating that writing is a process through which we arrive at a greater knowledge of ourselves." 


\section{APPENDIX B}

\section{INTERVIEW QUESTIONS (tutors)}

Take your time in replying to the questions. Try to give detailed responses and explain your answers. Write as much as you want; feel free to go off on tangents in order to make a larger point. Think and reflect upon your experiences. These are not meant to be restrictive questions. There are no "right" or "wrong" answers. Use specific examples whenever possible.

1) What makes a good tutor? Is there a guiding philosophy to what you do?

2) What is your role as a tutor? What should you do in a session? What shouldn't you do?

3) What are your goals and expectations from a session?

4) Do students generally share these goals/expectations? What can you do if the students have a different goal in mind? If possible, talk about specific situations and how you reacted.

5) What are the priorities in a tutoring session (i.e. what is most important, least important)? Are issues always addressed in accordance with this hierarchy? Why or why not?

6) Have you ever felt your ideals/tutoring philosophy compromised by a session? How? How did you react?

7) What sorts of situations do you find most difficult as a tutor? Describe specific problematic students or sessions.

8) Are there any unique or atypical approaches you use in tutoring? What makes them effective?

9) Have you, in your sessions, ever used instructional techniques or addressed issues in a way that might contradict basic writing center philosophy? Explain. How often do such circumstances occur?

10) Do you ever feel pressure to use tutoring methods that seem inappropriate for the situation?

11) How do the following affect your sessions and ideals as a tutor?

a) Institutional setting

b) the types of students you receive

c) instructor/departmental perceptions of the writing center

12) Do any of the aforementioned factors in question \#10 affect your ability to maintain collaborative focus and/or a positive dynamic with your student? 
13) Do you feel that the philosophy of your writing center accurately reflects your own feelings about writing? If not, how does your personal philosophy differ? Explain.

14) Do you feel that your training adequately prepared you for actual tutoring sessions? Why or why not?

15) What advice would you have for a neophyte tutor who is still "learning the ropes"?

You're finished! Thanks for participating. 


\section{APPENDIX C \\ INTERVIEW QUESTIONS (Writing Center Directors)}

Take your time in replying to the questions. Try to give detailed responses and explain your answers. Write as much as you want; feel free to go off on tangents in order to make a larger point. Think and reflect upon your experiences. These are not meant to be restrictive questions. There are no "right" or "wrong" answers. Use specific examples whenever possible.

1) What do you feel the role of your writing center is?

2) Do other departments understand that role? Do students understand that role? If not, why not?

3) What is the mission statement/guiding philosophy at your writing center?

4) Where does that philosophy come from? How do students react to it?

5) What makes a good tutor? What should he/she do? What shouldn't he/she do?

6) How are tutors trained at your writing center?

7) Do your trainees learn from watching videos of sessions? From role playing? Explain (if relevant).

8) Do you feel their training adequately prepares them to be an effective tutor? Why or why not?

9) Has a tutor in your writing center ever used unique or atypical methods of instruction? Have these methods ever contradicted basic writing center philosophy? How do you respond?

10) Is it ever appropriate for a tutor to use approaches that might contradict your center's basic philosophy? If so, when and why?

11) How do you respond to situations in which a student expects or requests a service that your center does not provide?

12) How does your institutional setting affect your writing center?

13) What is the most difficult part of your job? What is the easiest?

14) What is the most important piece of advice you can give a neophyte tutor?

\section{You're finished! Thanks for participating.}




\section{APPENDIX D}

\section{SURVEY QUESTIONS}

It will take approximately 5 minutes to complete this questionnaire.

Your participation in this study is completely voluntary. There are no foreseeable risks associated with this project. However, if you feel uncomfortable answering any questions, you can withdraw from the survey at any point.

Your survey responses are strictly confidential, and data from this research will be reported only in the aggregate. Your information will be coded and will remain confidential. If you have questions at any time about the survey or the procedures, you may contact Philip Sloan at the email address specified below.

Thank you very much for your time and support. Please start with the survey now by clicking on the Continue button below.

1.

Strongly Agree Neutral Disagree Strongly
Disagree
directors.

2.

\begin{tabular}{|c|c|c|c|c|}
\hline $\begin{array}{l}\text { Strongly } \\
\text { Agree }\end{array}$ & Agree & Neutral & Disagree & $\begin{array}{l}\text { Strongly } \\
\text { Disagree }\end{array}$ \\
\hline & $m$ & $m$ & 5 & $m$ \\
\hline
\end{tabular}

The student should determine the nature of the session.

3.

$\begin{array}{ccccc}\begin{array}{c}\text { Strongly } \\ \text { Agree }\end{array} & \text { Agree } & \text { Neutral } & \text { Disagree } & \begin{array}{c}\text { Strongly } \\ \text { Disagree }\end{array} \\ & B & B & & \end{array}$

Grammar is an important issue to address in a tutorial session.

4.

I sometimes address sentence-level mechanics first in a tutorial session.

$\begin{array}{cccc}\text { Strongly Agree Neutral Disagree } & \begin{array}{c}\text { Strongly } \\ \text { Disagree }\end{array}\end{array}$


5. The student and tutor usually have similar expectations from a session.

$\begin{array}{cccc}\begin{array}{c}\text { Strongly } \\ \text { Agree }\end{array} & \text { Agree Neutral Disagree } & \begin{array}{c}\text { Strongly } \\ \text { Disagree }\end{array}\end{array}$

6.

A tutor is student-centered in his/her instruction.

$\begin{array}{llll}\text { Strongly } & \text { Agree } & \text { Neutral Disagree } & \begin{array}{c}\text { Strongly } \\ \text { Disagree }\end{array} \\ \text { Agree } & & \end{array}$

7.

$\begin{array}{ccccc}\begin{array}{c}\text { Strongly } \\ \text { Agree }\end{array} & \text { Agree } & \text { Neutral } & \text { Disagree } & \begin{array}{c}\text { Strongly } \\ \text { Disagree }\end{array} \\ & & & \end{array}$
grade for the student.

8.

$\begin{array}{llll} & \begin{array}{c}\text { Strongly } \\ \text { Agree }\end{array} \\ \text { Most students are easy to work } & \text { Agree Neutral Disagree } & \text { Strongly } \\ \text { Disagree }\end{array}$

9.

$\begin{array}{llll}\text { Strongly } & \text { Agree } & \text { Neutral Disagree } & \begin{array}{c}\text { Strongly } \\ \text { Disagree }\end{array} \\ \text { Agree }\end{array}$

10.

Means are as important as ends in a tutorial session.

$\begin{array}{ccccc}\text { Strongly Agree Neutral Disagree } & \begin{array}{c}\text { Strongly } \\ \text { Disagree }\end{array}\end{array}$

A successful session is defined by the student, who must find his/her own way to a deeper analysis.

11. 


Strongly Agree Neutral Disagree Strongly
My training adequately prepared me for the tutor-
student dynamic that occurs in a session.

12.

$\begin{array}{ccccc}\text { Strongly } & \text { Agree } & \text { Neutral } & \text { Disagree } & \begin{array}{c}\text { Strongly } \\ \text { Disagree }\end{array}\end{array}$

13.

Strongly Agree Neutral Disagree
Agree

There are times when I felt like my own tutoring philosophy was threatened by a session.

14.

I would like to be able to proofread assignments.

$\begin{array}{ccccc}\begin{array}{c}\text { Strongly } \\ \text { Agree }\end{array} & \text { Agree } & \text { Neutral } & \text { Disagree } & \begin{array}{c}\text { Strongly } \\ \text { Disagree }\end{array}\end{array}$

15.

In some situations, it is necessary to be directive with a student.

$\begin{array}{ccccc}\begin{array}{c}\text { Strongly } \\ \text { Agree }\end{array} & \text { Agree } & \text { Neutral } & \text { Disagree } & \begin{array}{c}\text { Strongly } \\ \text { Disagree }\end{array} \\ & & & \end{array}$

16.

I try to avoid explicitly telling a student

gly

$\begin{array}{llll}\text { Strongly } & \text { Agree } & \text { Neutral Disagree } & \begin{array}{c}\text { Strongly } \\ \text { Disagree }\end{array} \\ \text { Agree } & & \end{array}$

17.

$\begin{array}{ccccc}\begin{array}{c}\text { Strongly } \\ \text { Agree }\end{array} & \text { Agree } & \text { Neutral Disagree } & \begin{array}{c}\text { Strongly } \\ \text { Disagree }\end{array}\end{array}$


18.

$\begin{array}{lllll} & \begin{array}{c}\text { Strongly } \\ \text { Agree }\end{array} & \text { Agree } & \text { Neutral Disagree } & \begin{array}{c}\text { Strongly } \\ \text { Disagree }\end{array} \\ \text { A tutor should not write on a student's } & & \end{array}$

19.

$\begin{array}{ccccc}\begin{array}{c}\text { Strongly } \\ \text { Agree }\end{array} & \text { Agree } & \text { Neutral } & \text { Disagree } & \begin{array}{c}\text { Strongly } \\ \text { Disagree }\end{array} \\ \mathbf{C} & \mathbf{C} & \mathbf{C} & \mathbf{C} & \mathbf{C}\end{array}$

20.

\begin{tabular}{|c|c|c|c|c|}
\hline $\begin{array}{c}\text { Strongly } \\
\text { Agree }\end{array}$ & Agree & Neutral & Disagree & $\begin{array}{l}\text { Strongly } \\
\text { Disagree }\end{array}$ \\
\hline$B$ & {[} & $\mathrm{E}$ & $E$ & 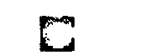 \\
\hline
\end{tabular}

I sometimes model sentences as examples for the student. inability to answer my questions.

21.

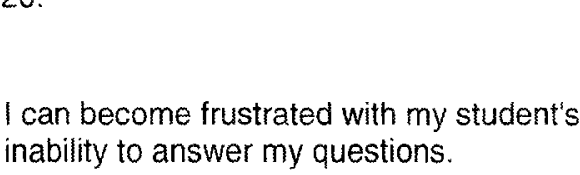

(1)

In a tutorial session, I am acting as a peer to my tutees.

22

It can conceivably be appropriate to edit a student's paper.

23.

I sometimes get defensive when asked to proofread something.

$\begin{array}{ccccc}\begin{array}{c}\text { Strongly } \\ \text { Agree }\end{array} & \text { Agree } & \text { Neutral Disagree } & \text { Strongly } \\ \text { Disagree }\end{array}$

24.

$\begin{array}{llll}\text { Strongly } & \text { Agree } & \text { Neutral Disagree } & \text { Strongly } \\ \text { Agree }\end{array}$


Agree

It can be useful to take an authoritarian

25.

$\begin{array}{cccc}\begin{array}{c}\text { Strongly } \\ \text { Agree }\end{array} & \text { Agree } & \text { Neutral Disagree } & \begin{array}{c}\text { Strongly } \\ \text { Disagree }\end{array}\end{array}$

The most crucial aspect of a tutorial session may be grammatical instruction.

26.

It is better that writing be "discovered" by a student than for writing to be explicitly taught.

Strongly Agree Neutral Disagree
Agree

27.

It is important that all sentences in a paper be
grammatically correct.

28.

If learners are allowed to make errors, these Strongly Agree Neutra Disagree Strongly Agree

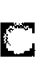
Disagree will be more difficult to correct later.

C

29. Students are often reticent to ask
questions.

30.

I am comfortable making grammar a priority in a session.

$\begin{array}{llll}\text { Strongly } & \text { Agree } & \text { Neutral Disagree } & \begin{array}{c}\text { Strongly } \\ \text { Disagree }\end{array} \\ \text { Agree } & & \end{array}$


31.

$\begin{array}{ccccc}\begin{array}{c}\text { Strongly } \\ \text { Agree }\end{array} & \text { Agree } & \text { Neutral } & \text { Disagree } & \begin{array}{c}\text { Strongly } \\ \text { Disagree }\end{array} \\ \square & \mathrm{C} & \mathrm{C} & \mathbf{C}\end{array}$

Students often want to address grammar issues first.

Strongly Agree Neutral Disagree Strongly

Agree $\quad$ Disagree

It is of paramount importance for tutors to

$\mathrm{E} B \mathrm{~B}$

facilitate learning at the student's point of need.

33.

Strongly Agree Neutral Disagree
Agree

There are sessions where all I tend to look at sentence-level mechanics and word choice.

34.

Strongly Agree Neutral Disagree Strongly
Agree

The instructional philosophy espoused by my writing center is appropriate and relevant to my actual experiences as a tutor.

35.

Strongly
Agree
Ido most of the talking in a typical
session.

Please contact penoose39@aol.com if you have any questions regarding this survey. 


\section{APPENDIX E}

\section{OLD INTERVIEW QUESTIONS}

1) What makes a good tutor? Is there a guiding philosophy to what you do?

2) What is your role as a tutor? What should you do in a session? What shouldn't you do?

3) What are your goals and expectations from a session?

4) Do students always share these goals/expectations? What can you do if the students have a different goal in mind? If possible, talk about specific situations and how you reacted.

5) What are the priorities in a tutoring session? Are issues always addressed in accordance with this hierarchy? Why or why not?

6) Have you ever felt your ideals/tutoring philosophy compromised by a session? How? How did you react?

7) Have you, in your sessions, ever used instructional techniques or addressed issues in a way that might contradict basic writing center philosophy? Explain. How often do such circumstances occur?

8) How does the institutional setting (situated at WSU) affect your sessions and ideals as a tutor? If possible, address issues of open admissions (ISP/CLL, etc), the types of students we receive, or specific instructor/departmental perceptions of the writing center.

9) Is it possible to maintain a collaborative discourse working within the constraints imposed by the institution (particularly those discussed in question \#8)? 